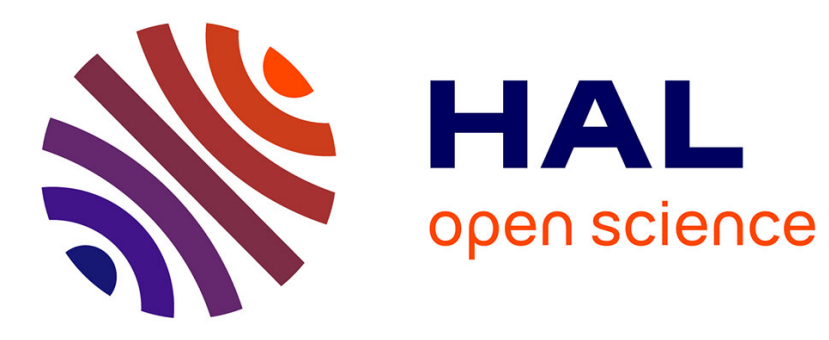

\title{
Three-dimensional Lead Iodide Perovskitoid Hybrids with High X-ray Photoresponse
}

\author{
Xiaotong Li, Yihui He, Mikael Kepenekian, Peijun Guo, Weijun Ke, Jacky \\ Even, Claudine Katan, Constantinos C Stoumpos, Richard Schaller, Mercouri \\ G Kanatzidis
}

\section{To cite this version:}

Xiaotong Li, Yihui He, Mikael Kepenekian, Peijun Guo, Weijun Ke, et al.. Three-dimensional Lead Iodide Perovskitoid Hybrids with High X-ray Photoresponse. Journal of the American Chemical Society, 2020, 142 (14), pp.6625-6637. 10.1021/jacs.0c00101 . hal-02509572

\section{HAL Id: hal-02509572 \\ https://hal.science/hal-02509572}

Submitted on 14 May 2020

HAL is a multi-disciplinary open access archive for the deposit and dissemination of scientific research documents, whether they are published or not. The documents may come from teaching and research institutions in France or abroad, or from public or private research centers.
L'archive ouverte pluridisciplinaire HAL, est destinée au dépôt et à la diffusion de documents scientifiques de niveau recherche, publiés ou non, émanant des établissements d'enseignement et de recherche français ou étrangers, des laboratoires publics ou privés. 


\title{
Three-dimensional Lead Iodide Perovskitoid Hybrids with High X-ray Photoresponse
}

Xiaotong Li, ${ }^{\dagger}$ Yihui He, ${ }^{\dagger}$ Mikaël Kepenekian, ${ }^{\S}$ Peijun Guo,${ }^{\dagger}$ Weijun Ke, ${ }^{\dagger}$ Jacky Even, ${ }^{\Perp}$ Claudine Katan, ${ }^{\S}$ Constantinos C. Stoumpos, ${ }^{\nabla}$ Richard D. Schaller, ${ }^{\dagger}$, and Mercouri G. Kanatzidis ${ }^{*}, \dagger$

†Department of Chemistry, Northwestern University, 2145 Sheridan Road, Evanston, Illinois 60208, United States

§Univ Rennes, ENSCR, INSA Rennes, CNRS, ISCR (Institut des Sciences Chimiques de Rennes), UMR 6226, Rennes F-35000, France

†enter for Nanoscale Materials, Argonne National Laboratory, 9700 South Cass Avenue, Lemont, Illinois 60439, United States

"Univ Rennes, INSA Rennes, CNRS, Institut FOTON, UMR 6082, Rennes F-35000, France

$\nabla$ Department of Materials Science and Technology, Voutes Campus, University of Crete, Heraklion GR-70013, Greece

\begin{abstract}
Large organic A cations cannot stabilize the 3D perovskite $\mathrm{AMX}_{3}$ structure because they cannot be accommodated in the cubo-octhedral cage (do not follow the Goldschmidt tolerance factor rule), and they generally template low-dimensional structures. Here we report that the large di-cation aminomethylpyridinium (AMPY), can template novel 3D structures which resemble conventional perovskites. They have the formula (xAMPY) $\mathrm{M}_{2} \mathrm{I}_{6}\left(\mathrm{x}=3\right.$ or $4, \mathrm{M}=\mathrm{Sn}^{2+}$ or $\mathrm{Pb}^{2+}$ ) which is doubled the $\mathrm{AMX}_{3}$ formula. However, because of the steric requirement of the Goldschmidt tolerance factor rule, it is impossible for ( $\mathrm{xAMPY}) \mathrm{M}_{2} \mathrm{I}_{6}$ to form proper perovskite structures. Instead, a combination of corner-sharing and edge-sharing connectivity is adopted in these compounds leading to the new 3D structures. DFT calculations reveal that the compounds are indirect-bandgap semiconductors with direct bandgaps presenting at slightly higher energies and dispersive electronic bands. The bandgaps of the $\mathrm{Sn}$ and $\mathrm{Pb}$ compounds are $\sim 1.7 \mathrm{eV}$ and $2.0 \mathrm{eV}$, respectively, which is slightly higher than the corresponding $\mathrm{AMI}_{3} 3 \mathrm{D}$ perovskites. The Raman spectra for the compounds are diffuse, with a broad rising central peak at very low frequencies around $0 \mathrm{~cm}^{-1}$, a feature that is characteristic of dynamical lattices, highly anharmonic, and dissipative vibrations very similar to the $3 \mathrm{D} \mathrm{AMX}_{3}$ perovskites. Devices of ( $\left.3 \mathrm{AMPY}\right) \mathrm{Pb}_{2} \mathrm{I}_{6}$ crystals exhibit clear photoresponse under ambient light without applied bias, reflecting a high carrier mobility $(\mu)$ and long carrier lifetime $(\tau)$. The devices also exhibit sizable X-ray generated photocurrent with a high $\mu \tau$ product of $\sim 1.2 \times 10^{-4} \mathrm{~cm}^{2} / \mathrm{V}$ and an X-ray sensitivity of $207 \mu \mathrm{C} \cdot \mathrm{Gy}^{-1} \cdot \mathrm{cm}^{-2}$.
\end{abstract}


Keywords: Metal halide hybrids, mixed cations, anomalous bandgap behavior, photoresponse, Xray detector. 


\section{Introduction}

Three-dimensional (3D) hybrid halide perovskites have achieved tremendous success in photovoltaic devices ${ }^{1-3}$ owing to their defect tolerance, long carrier lifetime and low trap density. ${ }^{4-6}$ These properties also enable photodetector, ${ }^{7} \mathrm{x}$-ray detection ${ }^{8}$ and $\gamma$-ray detection applications ${ }^{9-11}$. Alternative materials based on double perovskites ${ }^{12-15}$ and low-dimensional perovskites ${ }^{15-20}$ are also being explored as they enrich the structural diversity and property repertoire of the perovskite framework. The 3D perovskite structure which forms by the corner-sharing motif of the $\mathrm{MX}_{6}$ octahedra of $\mathrm{Pb}^{2+}$ and $\mathrm{Sn}^{2+}$ creates a favorable electronic band structure with very broad valence and conduction bands which facilitate photo-excited charge transport. ${ }^{21-22}$ It is this type of electronic band structure, along with the special lattice dynamics, that underpin the very promising optoelectronic properties of the perovskites. Theoretical DFT calculations of various metal halide structures show that the electronic band dispersions are larger in the corner-sharing motifs than in edge-sharing ones, while the face-sharing structures have relatively flat bands and poor charge transport. ${ }^{23-25}$ This raises the interesting question: is it possible to find structure motifs for $\mathrm{Pb}$ and Sn based hybrids beyond the perovskite paradigm that can still exhibit comparable electronic properties for practical applications? Currently, we cannot fully answer the question because the scope of non-perovskite halide hybrids with $\mathrm{Pb}$ and $\mathrm{Sn}$ is relatively limited.

The 3D perovskite structure has defined cages which are stabilized by the so called Goldschmidt tolerance factor, ${ }^{26}$ a geometrical constraint that must be met by the A cations in the general formula $\mathrm{AMX}_{3}\left(\mathrm{M}=\mathrm{Ge}^{2+}, \mathrm{Sn}^{2+}, \mathrm{Pb}^{2+} ; \mathrm{X}=\mathrm{Cl}^{-}, \mathrm{Br}^{-}, \mathrm{I}^{-}\right) .{ }^{5-6}$ So far, only three +1 A-site cations can maintain the 3D structures: $\mathrm{Cs}^{+}, \mathrm{CH}_{3} \mathrm{NH}_{3}{ }^{+}(\mathrm{MA})$, or $\mathrm{HC}\left(\mathrm{NH}_{2}\right)_{2}{ }^{+}(\mathrm{FA})$. When the A cation is as big as ethylenediammonium (en), it can replace some of the $\mathrm{M}^{2+}$ forming the "hollow" perovskites with decreasing mass densities as the amount of en increases, ${ }^{27-28}$. When it comes to $\mathrm{HOC}_{2} \mathrm{H}_{4} \mathrm{NH}_{3}{ }^{+}$ (hea) cation ${ }^{29-30}$, some $\mathrm{Pb}^{2+}$ and $\mathrm{I}^{-}$deficient channels are formed with the $\mathrm{Pb}^{2+}$ and $\mathrm{I}^{-}$ions partially replaced by the hea cation, and as a result, the volume of the unit cell is larger than that of the $\mathrm{MAPbI}_{3}$. For cations with three or more carbons, two-dimensional (2D) $)^{25,31-32}$ and onedimensional (1D) structures ${ }^{33}$ are formed to accommodate them. ${ }^{34}$ For example, the linear diammonium cations $\mathrm{NH}_{3} \mathrm{C}_{m} \mathrm{H}_{2 m} \mathrm{NH}_{3}{ }^{2+} \quad(\mathrm{m}=4-9)$ lead to the 2D $\left(\mathrm{NH}_{3} \mathrm{C}_{m} \mathrm{H}_{2 m} \mathrm{NH}_{3}\right)\left(\mathrm{CH}_{3} \mathrm{NH}_{3}\right)_{n-1} \mathrm{~Pb}_{n} \mathrm{I}_{3 n+1}(m=4-9, n=1-4)$ series. ${ }^{35}$ The cyclic diammonium cations $\mathrm{x}$-(aminomethyl)piperidium (xAMP, $\mathrm{x}=3$ or 4) template the Dion-Jacobson phases $(\mathrm{xAMP})\left(\mathrm{CH}_{3} \mathrm{NH}_{3}\right)_{n-1} \mathrm{~Pb}_{n} \mathrm{I}_{3 n+1}(\mathrm{n}=1-4) .{ }^{36} \mathrm{As}$ in the case of $\mathrm{x}$-aminomethylpyridium (AMPY) $(\mathrm{x}=$ 
2, 3 or 4) cations, they form 2D, OD and 1D structures with 2AMPY, 3AMPY and 4AMPY for bromide compounds, respectively. ${ }^{37}$ For iodide compounds, 2AMPY cation can form either 1D structure that incorporate crystalline $\mathrm{H}_{2} \mathrm{O}$ in the lattice or $2 \mathrm{D}$ structures that preclude $\mathrm{H}_{2} \mathrm{O}$, and these structures can be converted below $90{ }^{\circ} \mathrm{C} .{ }^{38-39}$ Recently, our group reported that 3AMPY and 4AMPY cations can also template multilayered 2D Dion-Jacobson phases (xAMPY)(MA) ${ }_{n}$ ${ }_{1} \mathrm{~Pb}_{n} \mathrm{I}_{3 n+1}(\mathrm{x}=3$ or $4, n=1-4) .{ }^{40}$ In many lower dimensional structures, however, the connectivity mode is not limited to corner-sharing only, edge-sharing and face-sharing ${ }^{31}$ modes are also commonly seen. These materials are no longer proper perovskites and can be referred to as "perovskitoids". 41

Here, we show that the XAMPY cations can stabilize 3D perovskitoid structures with $\mathrm{Sn}$ and $\mathrm{Pb}$ that consist of both corner-sharing and edge-sharing octahedra. The compounds have a double $\mathrm{AMX}_{3}$ formula, (xAMPY) $\mathrm{M}_{2} \mathrm{I}_{6}$, and theoretical DFT calculations show that their electronic structures resemble those of the $3 \mathrm{D} \mathrm{AMX}_{3}$ perovskites. The bandgaps of the new compounds are $\sim 0.5 \mathrm{eV}$ wider than the $\mathrm{AMX}_{3} 3 \mathrm{D}$ perovskites because the polyhedron connectivity is a mixture of corner-sharing and edge-sharing motifs. The bandwidths are large along the directions of cornersharing, leading to low carrier effective masses and the bandgaps still fall within the range for solar cell and X-ray radiation detector applications. Raman spectra reveal a broad response that is consistent with the loss of translational symmetry with phonons from across the Brillouin zone apparently contributing to scattering of the incident light, suggesting lattice phonon dynamics typical of liquids and high anharmonicity. Interestingly, this response is similar to the $3 \mathrm{D} \mathrm{MAPbX}$ perovskites whose lattices are dynamical and possess dual "crystal-liquid" characteristics, causing large polaron formation and good screening of charge carriers. In this context, we show that (3AMPY)Pb $\mathrm{I}_{6}$ exhibit promising optical and electronic properties suitable for radiation detector applications. They exhibit high X-ray sensitivity of $207 \mu \mathrm{C} \cdot \mathrm{Gy}^{-1} \cdot \mathrm{cm}^{-2}$ and robust photoresponse under ambient light even without applied bias, which can be attributed to its large carrier mobility and lifetime product.

\section{Experimental Section}

Starting Materials $\mathrm{PbI}_{2}(99.999 \%), \mathrm{SnCl}_{2} \cdot 2 \mathrm{H}_{2} \mathrm{O}(99 \%)$, hydroiodic acid (57 wt \% in $\mathrm{H}_{2} \mathrm{O}$, distilled, stabilized, 99.95\%), hypophosphorous acid solution (50 wt \% in $\mathrm{H}_{2} \mathrm{O}$ ), 3- 
(aminomethyl)pyridine (99\%) and 4-(aminomethyl)pyridine (98\%) were purchased from SigmaAldrich and used as received.

\section{Synthesis.}

(3AMPY)Pb ${ }_{2} I_{6}$ An amount of $2 \mathrm{mmol}(446.4 \mathrm{mg}) \mathrm{PbO}$ was dissolved in $2.5 \mathrm{~mL}$ concentrated HI solution under heating to boiling and vigorous stirring until a clear yellow solution was obtained. $0.5 \mathrm{mmol}(50.8 \mu \mathrm{L}) 3$-(aminomethyl)pyridine (3AMPY) was added to $0.5 \mathrm{~mL}$ hypophosphorous acid in a separate vial under stirring. The protonated 3AMPY solution was added to the previous solution under continuous heating at $240{ }^{\circ} \mathrm{C}$ and stirred for $5 \mathrm{~min}$. Then the temperature was lowered to $125^{\circ} \mathrm{C}$ until red crystals precipitated out. After one hour most crystals had precipitated out, the product was isolated by suction filtration from the hot solution and dried on the filtration funnel for a further $30 \mathrm{~min}$. Yield: $375 \mathrm{mg}, 22.7 \%$ based on total $\mathrm{Pb}$.

(4AMPY)Pb ${ }_{2} I_{6}$ An amount of $2 \mathrm{mmol}$ (446.4 mg) $\mathrm{PbO}$ was dissolved in $2.5 \mathrm{~mL}$ concentrated HI solution under heating to boiling and vigorous stirring until a clear yellow solution was obtained. $0.4 \mathrm{mmol}(40.6 \mu \mathrm{L})$ 4-(aminomethyl)pyridine (4AMPY) was added to $0.5 \mathrm{~mL}$ hypophosphorous acid in a separate vial under stirring. The protonated 4AMPY solution was added to the previous solution under continuous heating at $240{ }^{\circ} \mathrm{C}$ and stirred for $5 \mathrm{~min}$. Then the temperature was lowered to $125{ }^{\circ} \mathrm{C}$ until orange crystals precipitated out. After one hour most crystals had precipitated out, the product was isolated by suction filtration from the hot solution and dried on the filtration funnel for a further $30 \mathrm{~min}$. Yield: $281.3 \mathrm{mg}, 17.1 \%$ based on total $\mathrm{Pb}$.

(3AMPY) $\mathrm{Sn}_{2} \mathrm{I}_{6}$ An amount of $2 \mathrm{mmol}(451.3 \mathrm{mg}) \mathrm{SnCl}_{2} \cdot 2 \mathrm{H}_{2} \mathrm{O}$ was dissolved in $2.5 \mathrm{~mL}$ concentrated $\mathrm{HI}$ solution under heating to boiling and vigorous stirring until a clear yellow solution was obtained. $0.5 \mathrm{mmol}(50.8 \mu \mathrm{L}) 3 \mathrm{AMPY}$ was added to $0.5 \mathrm{~mL}$ hypophosphorous acid in a separate vial under stirring. The protonated 3AMPY solution was added to the previous solution under continuous heating at $240{ }^{\circ} \mathrm{C}$ and stirred for $5 \mathrm{~min}$. Then the temperature was lowered to $125^{\circ} \mathrm{C}$ until black crystals precipitated out. After one hour most crystals had precipitated out, the product was isolated by suction filtration from the hot solution and dried on the filtration funnel for a further $30 \mathrm{~min}$. Yield: $268.1 \mathrm{mg}, 24.2 \%$ based on total $\mathrm{Sn}$.

(4AMPY) $\mathrm{Sn}_{2} \mathrm{I}_{6}$ An amount of $2 \mathrm{mmol}(451.3 \mathrm{mg}) \mathrm{SnCl}_{2} \cdot 2 \mathrm{H}_{2} \mathrm{O}$ was dissolved in $2.5 \mathrm{~mL}$ concentrated HI solution under heating to boiling and vigorous stirring until a clear yellow solution was obtained. $0.5 \mathrm{mmol}(50.8 \mu \mathrm{L}) 4 \mathrm{AMPY}$ was added to $0.5 \mathrm{~mL}$ hypophosphorous acid in a separate vial under stirring. The protonated $3 \mathrm{AMPY}$ solution was added to the previous solution 
under continuous heating at $240{ }^{\circ} \mathrm{C}$ and stirred for $5 \mathrm{~min}$. Then the temperature was lowered to $125^{\circ} \mathrm{C}$ until dark red crystals precipitated out. After one hour most crystals precipitated out, the product was isolated by suction filtration from the hot solution and dried on the filtration funnel for a further $30 \mathrm{~min}$. Yield: $231.2 \mathrm{mg}, 20.8 \%$ based on total $\mathrm{Sn}$. $(3 A M P Y)_{1-x}(4 A M P Y)_{x} S_{2} I_{6}$ An amount of $2 \mathrm{mmol}(451.3 \mathrm{mg}) \mathrm{SnCl}_{2} \cdot 2 \mathrm{H}_{2} \mathrm{O}$ was dissolved in 2.5 $\mathrm{mL}$ concentrated HI solution under heating to boiling and vigorous stirring until a clear yellow solution was obtained. 0.5(1-x) mmol 3AMPY and 0.5x mmol 4AMPY ( $\mathrm{x}=0.25,0.5,0.75)$ were added to $0.5 \mathrm{~mL}$ hypophosphorous acid in a separate vial under stirring. The protonated solution was added to the previous solution under continuous heating at $240{ }^{\circ} \mathrm{C}$ and stirred for $5 \mathrm{~min}$. Then the temperature was lowered to $125^{\circ} \mathrm{C}$ until black crystals precipitated out. After one hour most crystals precipitated out, the product was isolated by suction filtration from the hot solution and dried on the filtration funnel for a further $30 \mathrm{~min}$.

$(3 A M P Y)\left(\mathrm{Pb}_{1-x} \mathrm{Sn}_{x}\right)_{2} \mathrm{I}_{6}$ An amount of $2 \mathrm{x} \mathrm{mmol} \mathrm{SnCl}_{2} \cdot 2 \mathrm{H}_{2} \mathrm{O}$ and $2(1-\mathrm{x}) \mathrm{mmol} \mathrm{PbO}(\mathrm{x}=0.25,0.5$, $0.75)$ were dissolved in $2.5 \mathrm{~mL}$ concentrated HI solution under heating to boiling and vigorous stirring until a clear yellow solution was obtained. $0.5 \mathrm{mmol}(50.8 \mu \mathrm{L}) 3 \mathrm{AMPY}$ was added to 0.5 $\mathrm{mL}$ hypophosphorous acid in a separate vial under stirring. The protonated 3AMPY solution was added to the previous solution under continuous heating at $240{ }^{\circ} \mathrm{C}$ and stirred for $5 \mathrm{~min}$. Then the temperature was lowered to $125{ }^{\circ} \mathrm{C}$ until black crystals precipitated out. After one hour most crystals had precipitated out, the product was isolated by suction filtration from the hot solution and dried on the filtration funnel for a further $30 \mathrm{~min}$.

Single Crystal Structure. Single-crystal X-ray diffraction experiments were performed using a STOE IPDS II or IPDS $2 \mathrm{~T}$ diffractometer with Mo K $\alpha$ radiation $(\lambda=0.71073 \AA)$ and operating at $50 \mathrm{kV}$ and $40 \mathrm{~mA}$. Integration and numerical absorption corrections were performed using the XAREA, X-RED, and XSHAPE programs. The structures were solved by charge flipping and refined by full-matrix least-squares on $\mathrm{F}^{2}$ using the Jana 2006 package. ${ }^{42}$ The PLATON ${ }^{43}$ software was used to identify the twinning domains and validate the space groups of the compounds.

Computational details. First-principles calculations are based on density functional theory (DFT) as implemented in the SIESTA package. ${ }^{44-45}$ Calculations have been carried out on experimental structures with the GGA functional in the revPBE form. ${ }^{46}$ Core electrons are described with Troullier-Martins pseudopotentials, ${ }^{47}$ while valence wavefunctions are developed over double- $\zeta$ polarized basis set of finite-range numerical pseudoatomic orbitals. ${ }^{48}$ In our calculations, spin-orbit 
coupling is taken into account through the on-site approximation as proposed by FernándezSeivane et al. ${ }^{49}$ In all cases, an energy cutoff of 150 Ry for real-space mesh size has been used.

Detector Fabrication and Performance Measurements. The ( $3 \mathrm{AMPY}) \mathrm{Pb}_{2} \mathrm{I}_{6}$ crystal was used to fabricate the detector with the structure of $\mathrm{Ga} /(3 \mathrm{AMPY}) \mathrm{Pb}_{2} \mathrm{I}_{6} / \mathrm{Au}$. Au electrodes were prepared by conductive adhesive paint. Ga electrode was prepared by spreading liquid Ga metal on the surface. The I - V curves were measured using a Keithley 6517B electrometer. The photoconductivity measurement was done under ambient light under AM1.5 G simulated irradiation with a standard solar simulator (Abet Technologies) with a flux of $10 \mathrm{~mW} / \mathrm{cm}^{2}$. The X-ray response was measured using an uncollimated X-ray source, generated by Amptek Ag Mini X-ray tube with the operation tube voltage of $50 \mathrm{kV}$. During measurement, the X-ray beam was filtered by Al pad for reducing the dose rate. The dose rate was tuned by changing the tube current from 10 to $60 \mu \mathrm{A}$.

\section{Results and Discussion}

Synthesis. To avoid the previously reported 2D perovskite (xAMPY) $\mathrm{PbI}_{4}$ structures, which formed when the ratio of $\mathrm{Pb}$ and AMPY starting materials is $1: 1,{ }^{40}$ we used a $4: 1$ ratio which led to the new compounds. After all reactants dissolved under stirring and boiling, if the solution was cooled directly to the room temperature, the compounds could not form, and instead light-yellow phases precipitated out. These are hydrated phases formed, which were also observed as intermediates in the synthesis of the $2 \mathrm{D}(\mathrm{xAMPY}) \mathrm{PbI}_{4}$ structures. ${ }^{40}$ Similar orange hydrated phases were also observed for the Sn analogues. Therefore, to avoid these light-yellow phases, the hot plate temperature needs to be lowered from $240^{\circ} \mathrm{C}$ to $125^{\circ} \mathrm{C}$ (right below the boiling point of HI) to keep the solution hot and prevent their precipitation. It is worth mentioning that the solution temperature cannot exceed the boiling point of concentrated HI $\left(\sim 127^{\circ} \mathrm{C}\right)$ which is a "physical constant" for the given concentration of solutes. The excess heat produced by the $240{ }^{\circ} \mathrm{C}$ temperature on the hot plate is only relevant in assessing the rate of the solvent evaporation rather than the actual temperature of the reaction and was chosen to accelerate the synthetic process. The solutions need to be very concentrated so that the desired phase can still precipitate out at $125^{\circ} \mathrm{C}$. Plate-like crystals started to form from the hot $125^{\circ} \mathrm{C}$ solution within one hour, and the crystal growth process was completed within one more hour. The formed crystals were filtered by suction filtration directly from the hot solution to avoid the formation of the hydrated phases. The color of 
the (3AMPY) $\mathrm{Pb}_{2} \mathrm{I}_{6}$ crystal is red while that of (4AMPY) $\mathrm{Pb}_{2} \mathrm{I}_{6}$ is orange. The colors of (3AMPY) $\mathrm{Sn}_{2} \mathrm{I}_{6}$ and (4AMPY) $\mathrm{Sn}_{2} \mathrm{I}_{6}$, are black and dark red, respectively, and all the crystals are plate-like in shape. The pictures of the crystals are shown as insets in Figure S1, and the experimental power X-ray diffraction (PXRD) patterns match the calculated ones, showing that pure phases are obtained during the synthesis. Both Sn compounds have the same crystal structure as (3AMPY) $\mathrm{Pb}_{2} \mathrm{I}_{6}$, which makes mixing both $\mathrm{A}^{+}$and $\mathrm{M}^{2+}$ cations to form isostructural alloys possible. The mixed $\mathrm{A}^{+}$cation compounds exhibit a continuous color change between (3AMPY)Sn ${ }_{2} \mathrm{I}_{6}$ and (4AMPY) $\mathrm{Sn}_{2} \mathrm{I}_{6}$. For the mixed $\mathrm{Pb} / \mathrm{Sn}$ compounds, all crystals are black as their optical bandgaps are smaller than both parent compounds (see below).

Crystal structures. The general formula of the new materials is ( $\mathrm{xAMPY}) \mathrm{M}_{2} \mathrm{I}_{6},(\mathrm{x}=3$ or $4, \mathrm{M}=$ $\mathrm{Pb}^{2+}$ or $\mathrm{Sn}^{2+}$ ), which is equivalent to a doubled 3D perovskite $\mathrm{AMI}_{3}$ formula where two $\mathrm{A}^{+}$cations are substituted by a single +2 xAMPY cation. However, the large XAMPY cations template different structures with a combination of corner-sharing and edge-sharing octahedra, giving rise to two unique metal-halide frameworks. All compounds crystallize in the polar monoclinic space groups $I a / I m$, with the results of structural refinement shown in Table 1, and detailed crystallographic data provided in Tables S1-S5. It is worth mentioning that the inorganic structures are noncentrosymmetric locally (i.e. in a single unit cell), but in the long-range bulk they tend to be centrosymmetric as the dipoles cancel out on average. This picture is in line with the dynamic crystal structure of the halide perovskites (especially at room temperature) which makes such an equivocal structural interpretation possible (see detailed discussion of the Raman spectra below). We chose the noncentrosymmetric space groups to avoid the disorder in the model as we have explained in detail for 2D structure refinements previously. ${ }^{50}$ (3AMPY) $\mathrm{Sn}_{2} \mathrm{I}_{6}$ and (4AMPY) $\mathrm{Sn}_{2} \mathrm{I}_{6}$ adopt the same space group as $(3 \mathrm{AMPY}) \mathrm{Pb}_{2} \mathrm{I}_{6}(\mathrm{Im})$, whereas the (4AMPY) $\mathrm{Pb}_{2} \mathrm{I}_{6}$ compound exhibits a different space group $(I a)$. Therefore, the two types of structures will be discussed separately. The unit cells in both cases consist of four layers of octahedra, summing up to a lattice parameter of $\sim 25 \AA$, which represents a 4-fold supercell of the basic octahedral motif $(4 \times \sim 6.3 \AA)$.

Crystal structure of (4AMPY)Pb $\mathbf{b}_{\mathbf{2}} \mathbf{I}_{6}$. There are four crystallographically independent $\mathrm{Pb}$ atoms forming four distinct octahedra in the (4AMPY) $\mathrm{Pb}_{2} \mathrm{I}_{6}$ structure (Figure 1a), and two of them are connected by edge-sharing to form dimers, which then further connect through corner-sharing to 
other dimers to form continuous layers extending along the $b c$ crystallographic plane. Four edgesharing dimers connect through corners across the individual layers to form triangular-shaped voids (Figure 2a, 2b). The layers then stack by corner-connect along the $a$-axis (stacking axis) to complete the anionic inorganic 3D framework (Figure 2c). The characteristic size and shape of the 4AMPY act as a template, forming a large isosceles triangle-shaped cavity around which the network structure is built. The 4AMPY cation lies in the plane of the layers and perpendicular to the stacking direction in the channels, a configuration that is imposed by the charge density distribution of the organic atoms. Although all layers are the same, they stack in pairs. This is shown by the yellow and purple layers in Figure 2a-c. Within a pair the layers stack in an eclipsed manner. Between pairs the stacking is accomplished by a $1 / 2 \times 1 / 2$ shift along the $b$ and $c$ axes, Figure $2 \mathrm{~d}$. The two adjacent bilayers between pairs are symmetry-related by glide planes. Viewed along the $a$-axis, the lattice contains rhombus-shaped channels (Figure 2d).

Crystal structure of (3AMPY) $\mathbf{M}_{2} \mathbf{I}_{6}\left(\mathbf{M}=\mathbf{P b}^{2+}\right.$ or $\left.\mathbf{S n}^{2+}\right)$. The structure of ( $\left.3 \mathrm{AMPY}\right) \mathrm{Pb}_{2} \mathrm{I}_{6}$ consists of six distinct $\mathrm{Pb}$ atoms (Figure $1 \mathrm{~b}$ ), and the basic motif is also dimers formed by two edge-sharing octahedra of adjacent $\mathrm{Pb}$ atoms. Its structure is different from that of (4AMPY) $\mathrm{Pb}_{2} \mathrm{I}_{6}$ in the interconnectivity of the edge-sharing dimers. In this case there are two chemically distinct types of layers. The first kind consists of corner-sharing merging from four dimer to form rectangular cavities instead of triangles (Figure 3a, c), and they are symmetry-related by a mirror plane. The second kind is the same as the one described above in the (4AMPY) $\mathrm{Pb}_{2} \mathrm{I}_{6}$ structure with triangular cavities (Figure 3b, d). The structure of (3AMPY) $\mathrm{Pb}_{2} \mathrm{I}_{6}$ can be thought as stacking of these layers in an alternating fashion along the $b$ direction, Figures $3 \mathrm{e}$. The triangular and rectangular voids containing the organic cations interchange across the stacking $b$ axis every other layer, Figure $3 \mathrm{f}$.

The $\mathrm{Sn}$ analogues crystallize in the ( $3 \mathrm{AMPY}) \mathrm{Pb}_{2} \mathrm{I}_{6}$ structure type. Similar to the ( $\left.3 \mathrm{AMPY}\right) \mathrm{Pb}_{2} \mathrm{I}_{6}$ structure, each of the four layers in the unit cell adopt a different connection motif, as shown in Figure 3a-d. Figure 4 shows the structures from a side view and the connection motif for the bottom layer. The difference in distortion between (3AMPY) $\mathrm{Sn}_{2} \mathrm{I}_{6}$ and (4AMPY) $\mathrm{Sn}_{2} \mathrm{I}_{6}$ can be seen from the close inspection of the bottom layer of the two structures. Specifically, the shape of the cage is a regular rectangle for ( $3 \mathrm{AMPY}) \mathrm{Sn}_{2} \mathrm{I}_{6}$, Figure $4 \mathrm{~b}$, whereas for $(4 \mathrm{AMPY}) \mathrm{Sn}_{2} \mathrm{I}_{6}$ the rectangle is significantly deformed, Figure 4d. 
Because of the strong links to the electronic properties, it is important to analyze the connectivity types of the metal iodide octahedra in these structures as well as the M-I-M angles and bonding distortions. To simplify the discussion, we only consider the M-I-M angles of corner-sharing connectivity, since they are the special feature in perovskites and most relevant to the charge transport and electronic band dispersion. The M-I-M angles can be divided into the "equatorial" M-I-M angles which are perpendicular to the stacking axis and the "axial" M-I-M angles that align parallel to the stacking axis, Table 2. For the $\mathrm{Pb}$ compounds, the (4AMPY) $\mathrm{Pb}_{2} \mathrm{I}_{6}$ structure has smaller equatorial angles than (3AMPY) $\mathrm{Pb}_{2} \mathrm{I}_{6}$ because the $\mathrm{Pb}-\mathrm{I}-\mathrm{Pb}$ acute angles of the triangular cavity are much smaller than $180^{\circ}$. The (3AMPY) $\mathrm{Pb}_{2} \mathrm{I}_{6}$ structure has half the number of triangular cavity and half rectangular cavity, where the $\mathrm{Pb}-\mathrm{I}-\mathrm{Pb}$ angles for the rectangular cavity are almost $180^{\circ}$. Therefore, the ( $\left.3 \mathrm{AMPY}\right) \mathrm{Pb}_{2} \mathrm{I}_{6}$ structure has on average larger equatorial $\mathrm{Pb}-\mathrm{I}-\mathrm{Pb}$ angles than the (4AMPY) $\mathrm{Pb}_{2} \mathrm{I}_{6}$ structure. For the Sn compounds, even though the connection motif is the same, the Sn-I-Sn angles are different, as seen from the large deformation of the rectangular cavity (Figure 4d). The (3AMPY) $\mathrm{Sn}_{2} \mathrm{I}_{6}$ structure has larger equatorial and axial $\mathrm{Sn}-\mathrm{I}-\mathrm{Sn}$ angles, so the average Sn-I-Sn angles are also larger than the (4AMPY) $\mathrm{Sn}_{2} \mathrm{I}_{6}$ structure, Table 2.

We can also compare the average distortion levels of individual octahedra. This structural distortion can be quantified by defining the distortion index (D) and bond angle variance $\left(\sigma^{2}\right)$ of the octahedra by the variance of the M-I bond-length and M-I-M bond-angle from the average value calculated by the Vesta software, ${ }^{51-52}$ as shown in equation (1) and (2), where $l_{a v}$ is the average M-I bond distance, $l_{i}$ are the individual bond-length and $\phi_{i}$ is the individual bond-angle. For the structures with multiple independent octahedra, the average values are used. The distortion index and bond angle variance are significantly higher in the (4AMPY) $\mathrm{Sn}_{2} \mathrm{I}_{6}$ than those in the (3AMPY) $\mathrm{Sn}_{2} \mathrm{I}_{6}$ (Table 2), and the values for (3AMPY) $)_{0.5}(4 \mathrm{AMPY})_{0.5} \mathrm{Sn}_{2} \mathrm{I}_{6}$ are between the two parent compounds. The structures of the $\mathrm{Pb}$ compounds are less distorted and the corresponding the $\mathrm{D}$ and $\sigma^{2}$ values are shown in Table 2.

$$
\begin{aligned}
D & =\frac{1}{6} \sum_{i}^{6} \frac{\left|l_{i}-l_{a v}\right|}{l_{a v}} \\
\sigma^{2} & =\sum_{i=1}^{12}\left(\phi_{i}-90\right)^{2} / 11
\end{aligned}
$$

The similarity of structures between ( $3 \mathrm{AMPY}) \mathrm{Pb}_{2} \mathrm{I}_{6}$ and ( $3 \mathrm{AMPY}$ ) $\mathrm{Sn}_{2} \mathrm{I}_{6}$ makes it possible to mix the $\mathrm{M}^{2+}$ cations to form the (3AMPY) $\left(\mathrm{Pb}_{1-x} \mathrm{Sn}_{x}\right)_{2} \mathrm{I}_{6}$ series with $x=0.25,0.5$ and 0.75 . The structure 
of (3AMPY)PbSnI $6(\mathrm{x}=0.5)$ adopts the same space group as the two parent compounds, and the unit cell dimensions lie in between (3AMPY) $\mathrm{Pb}_{2} \mathrm{I}_{6}$ and ( $3 \mathrm{AMPY}$ ) $\mathrm{Sn}_{2} \mathrm{I}_{6}$ (as shown Table 1). For $\mathrm{x}$ $=0.5$, the actual ratio of $\mathrm{Sn}$ and $\mathrm{Pb}$ is obtained by refining the occupancy of the $\mathrm{M}^{2+}$ site, with 1.09 $\mathrm{Sn}: 0.91 \mathrm{~Pb}$ close to the stoichiometric reaction ratio $(1: 1)$.

Electronic structure calculations. We calculated the electronic band structures using DFT with the experimentally obtained structures. Note that in the case of 3AMPY and 4AMPY organic cations, the well-known bandgap underestimation of GGA functionals causes the artificial appearance of molecular states from the organic cation within the band of the inorganic lattice. This is caused by the incorrect positions of the conduction and valence band extrema with respect to the lowest unoccupied molecular orbital (LUMO) of the organic cations. In order to circumvent this artifact, we performed calculations by substituting the organic cations with an estimated background charge. This way, the misplaced molecular cation states no longer appear in the band structure, while the band structure arising from the inorganic lattice is not dramatically affected (Figure S2a, b). All four compounds (xAMPY) $\mathrm{M}_{2} \mathrm{I}_{6}\left(\mathrm{x}=3\right.$ or $4, \mathrm{M}=\mathrm{Sn}^{2+}$ or $\mathrm{Pb}^{2+}$ ) are indirect bandgap semiconductors. For the Sn compounds, the valence band maxima (VBM) show up at the A point while the conduction band minima $(\mathrm{CBM})$ are at the $\Gamma$ point (Figure $5 \mathrm{a}, \mathrm{b}$ ). The calculated bandgaps of the indirect transition are $0.81 \mathrm{eV}$ and $0.80 \mathrm{eV}$ for the $(3 \mathrm{AMPY}) \mathrm{Sn}_{2} \mathrm{I}_{6}$ and (4AMPY) $\mathrm{Sn}_{2} \mathrm{I}_{6}$, respectively.

Despite the indirect bandgap, which may account for the weak photoluminescence (PL) at room temperature (see below), there is a closely lying, slightly larger direct bandgap at the $\Gamma$ point which can account for the significant optical absorption exhibited by these materials. As shown in Figure S2c, the $\mathrm{CB}$ and VB wavefunctions display linear combinations of orbitals both at the $A$ and $\Gamma$ points, which are favorable for direct dipolar electric transitions. The CB edge wavefunctions are indeed based on empty $p$-orbitals located on the $\mathrm{Pb}$ atoms and the $\mathrm{VB}$ edge wavefunctions on combinations of filled $p$-orbitals located on the iodine atoms and on filled $s$-orbitals located on the $\mathrm{Pb}$ atoms. These linear combinations of orbitals are typical of halide perovskites and stand at the origin of their remarkable optoelectronic properties. These strong direct optical transitions are in principle competing with indirect optical transitions between the $\mathrm{A}$ and $\Gamma$, i.e. from the $\mathrm{VB}(\mathrm{A})$ to the $\mathrm{CB}(\Gamma)$ and from the $\mathrm{VB}(\Gamma)$ to the $\mathrm{CB}(\mathrm{A})$, which is in sharp contrast to the conventional indirect semiconductors such as $\mathrm{Si}$, where the direct transition is very weak. ${ }^{53}$ 
The octahedra in the $b$ direction (for the Sn compound) are connected in corner-sharing mode, while in the other two directions there is a combination of corner-sharing and edge-sharing. Therefore, the $Г Y$ (MA) direction in the Brillouin zone, which corresponds to the $b$ direction in the real space, is the most energy dispersive direction for both VB and CB. This is in marked contrast to the other crystallographic directions where the octahedra share edges and the associated electronic bands are much less dispersive. This is consistent with our understanding that the cornersharing motif results in larger band dispersions than the edge-sharing one, followed by the facesharing motif. ${ }^{23-25}$

The $\mathrm{Pb}$ compounds have relatively flat valence bands and dispersive conduction bands. The VBM show up at the $\mathrm{Y}$ point while the $\mathrm{CBM}$ at the $\Gamma$ point. The (3AMPY) $\mathrm{Pb}_{2} \mathrm{I}_{6}$ and $(4 \mathrm{AMPY}) \mathrm{Pb}_{2} \mathrm{I}_{6}$ compounds exhibit larger calculated bandgaps than the Sn analogs at $1.41 \mathrm{eV}$ and $1.44 \mathrm{eV}$ (Figure $5 \mathrm{c}, \mathrm{d})$, which match the experimental trend. The (4AMPY)Pb ${ }_{2} \mathrm{I}_{6}$ shows strong differences from the other three compounds, with the VBM and CBM showing up in different positions in the Brillouin zone, which reflects its different crystallographic structure.

It is notable that the VBM and CBM of the $\mathrm{Pb}$ compounds are much less dispersive than the $\mathrm{Sn}$ analogs and this is also reflected in the computed carrier effective masses that are at least two times higher for $\mathrm{Pb}$ (Table 3). The strong spin-orbit coupling (SOC) pushes the filled $6 \mathrm{~s}$ based bands of the $\mathrm{Pb}$ perovskites lower in energy compared to the $5 \mathrm{~s}$ bands of the $\mathrm{Sn}$ perovskites, decreasing their contribution to the VBM. ${ }^{54}$ The significant energy stabilization of the $6 \mathrm{~s}$ based bands of the $\mathrm{Pb}$ perovskites result in narrowing of the valence bands. This trend, also observed in the 3D perovskites, suggests that the Sn compounds should have overall better hole and electron mobilities. $^{21}$ In the case of Sn perovskites, however, a strong anisotropy appears when looking closely at hole and electron effective masses. Indeed, the carrier effective masses in the cornersharing direction $\left(\mathrm{m}_{\mathrm{h}} \|\right.$ and $\left.\mathrm{m}_{\mathrm{e}} \|\right)$ are significantly smaller than the masses taken perpendicular to that direction $\left(\mathrm{m}_{\mathrm{h}}{ }^{\perp}\right.$ and $\mathrm{m}_{\mathrm{e}}{ }^{\perp}$, see Table 3$)$. The contrast is greater for electrons with a ratio $\mathrm{m}_{\mathrm{e}} \| / \mathrm{m}_{\mathrm{e}}{ }^{\perp}$ larger than 20 for 3AMPY and 4AMPY, but is also strong for holes with a ration $\mathrm{m}_{\mathrm{h}} \| / \mathrm{m}_{\mathrm{h}}{ }^{\perp}$ greater than 10 and 3.5 for 3AMPY and 4AMPY, respectively. This indicates that the Sn compounds are considerably more anisotropic in an electronic transport sense despite the 3D structure of the framework. The anisotropy also exists for $\mathrm{Pb}$ compounds but is less pronounced, in particular for holes with $m_{h} \| / m_{h}{ }^{\perp}$ ratios lesser than 2 . These results call for a careful orientation of the 
compounds within a device for full utilization of the charge mobilities. Given the energy dispersive nature of the conduction bands of the $\mathrm{Pb}$ compounds, the $\mathrm{m}_{\mathrm{e}}$ is favorably small and suggests good electron transport properties.

Raman Spectra. The room-temperature Raman spectra of the compounds, shown in Figure 6, consist of very broad, low intensity peaks. displaying similar behavior to the conventional 3D $\mathrm{AMX}_{3}$ structures. The spectra are diffuse, composed of a central peak with a notable spectral continuum from very broad Raman transitions. For the $\mathrm{Pb}$ compounds, the peaks at lower frequencies $\left(<70 \mathrm{~cm}^{-1}\right)$ correspond to the bending modes of $\left[\mathrm{PbI}_{6}\right]^{4-}$ octahedra while the peak at $\sim 100 \mathrm{~cm}^{-1}$ corresponds to the $\left[\mathrm{PbI}_{6}\right]^{4-}$ stretching modes. ${ }^{55}$ The Raman spectra for the Sn compounds are even more diffuse, with one broad peak expanding the measurement range. The broad central peak located around $0 \mathrm{~cm}^{-1}$ betrays loss of translational symmetry and is characteristic of dynamic atomic disorder, highly anharmonic, and dissipative vibrations. ${ }^{56-57}$ This type of room temperature Raman spectrum has been observed in crystalline $\mathrm{MAPbI}_{3}, \mathrm{MAPbBr}_{3}$ and $\mathrm{CsPbBr}$, perovskites which are known to have soft distortive lattices and interestingly similar to those of fluids. ${ }^{55,58}$ In essence the broad central peaks suggests one can view these anharmonic crystalline structures as vibrating in almost all frequencies. This behavior is attributed to local polar fluctuations and high anharmonicity that derive from the $6 \mathrm{~s}^{2}\left(5 \mathrm{~s}^{2}\right)$ lone pair activity of $\mathrm{Pb}^{2+}\left(\mathrm{Sn}^{2+}\right)$ and halide motion. These fluctuations are intrinsic to the general metal-halide perovskite structure and the presence of corner-sharing octahedra and less so to any dipolar organic cation. ${ }^{54}$ This fluid-like behavior in the inorganic lattice is believed to cause the beneficial defect tolerant properties of 3D perovskites and implies that the title (3AMPY) $\left(\mathrm{Pb}_{1-x} \mathrm{Sn}_{x}\right)_{2} \mathrm{I}_{6}$ and (4AMPY)( $\left.\mathrm{Pb}_{1-x} \mathrm{Sn}_{x}\right)_{2} \mathrm{I}_{6}$ compounds also possess similar characteristics considering the large fraction of corner-sharing octahedra.

Optoelectronic properties. The absorption spectra of the four parent compounds are shown in Figure $\mathrm{S} 3$, and the absorption spectra of the $(3 \mathrm{AMPY})\left(\mathrm{Pb}_{1-x} \mathrm{Sn}_{x}\right)_{2} \mathrm{I}_{6}$ series are presented in Figure 7a. An optical feature near the optical band gap similar to an excitonic resonance is prominent only for the pure $\mathrm{Pb}$ compound. We may infer that an excitonic resonance can be barely seen in the $\mathrm{Sn}$ or the mixed $\mathrm{Sn} / \mathrm{Pb}$ compounds, indicating lower excitonic binding energies for the Sn-based perovskites. ${ }^{59-60}$ The bandgap values (Figure 7b, d) were extracted from the low-energy slope of the Tauc plot (Figure S4). As suggested above by the electronic structure calculations, the compounds are technically indirect bandgap semiconductors but practically seem to behave as 
direct bandgap materials. This can explain the experimental results that some of the absorption spectra (especially those of mixed AMPY cations, shown in Figure 7c) have a low energy tail (likely indicative of structural disorder) and the PL intensities are low (compared to perovskite compounds) at room temperature (Figure S3b, d). Though the estimated bandgaps are slightly different when the Tauc plots are drawn based on the indirect (Figure S4) and direct bandgap models (Figure S5), the trend is the same among the compounds.

As it is typical in halide perovskites, the $\mathrm{Sn}$ compounds exhibit smaller bandgap than the $\mathrm{Pb}$ ones. The intermediate mixed $\mathrm{Pb} / \mathrm{Sn}$ compounds, however, show anomalous trend and exhibit smaller bandgaps than the parent $\mathrm{Sn}$ and $\mathrm{Pb}$ compounds. This trend, called the bowing effect, defies the so-called Vegard's law and comes from the fact that the Sn compound has deeper conduction band minimum (CBM) and the $\mathrm{Pb}$ compound has shallower valence band maximum (VBM) with respect to each other. ${ }^{61-62}$ Because of this trend, most alloy combinations of $\mathrm{Sn}$ and $\mathrm{Pb}$ will generate lower bandgaps than the Sn compounds. ${ }^{63-64}$ As for the mixed cation (3AMPY) $)_{1-x}(4 \mathrm{AMPY})_{x} \mathrm{Sn}_{2} \mathrm{I}_{6}$ series, the bandgaps of the intermediate compounds do fall between the two parent ones following Vegard's law. The bandgaps enlarge as the fraction of 4AMPY increases, even though the trend is not perfectly linear.

In $2 \mathrm{D}$ perovskites, the bandgaps are related to the distortion level defined by the M-I-M angles. ${ }^{65}$ As discussed previously, we simplify the structure by only looking at the corner-sharing M-I-M angles (Table 2). In the present case, the average $\mathrm{Pb}-\mathrm{I}-\mathrm{Pb}$ angles for the $(3 \mathrm{AMPY}) \mathrm{Pb}_{2} \mathrm{I}_{6}$ structure are larger because of the coexistence of the triangular and rectangular cavities, while for the (4AMPY) $\mathrm{Pb}_{2} \mathrm{I}_{6}$ structure, there are only triangular cavities with acute $\mathrm{Pb}-\mathrm{I}-\mathrm{Pb}$ angles (Table 2). Therefore, for the (3AMPY) $\mathrm{Pb}_{2} \mathrm{I}_{6}$ structure the $\mathrm{Pb}$ s- and I p-orbitals have better overlap in the direction of charge transport, resulting in a smaller bandgaps. For both the Sn compounds, even though the connection motif is the same, the (4AMPY) $\mathrm{Sn}_{2} \mathrm{I}_{6}$ structure has deformed rectangular cavities (because of more distorted $\mathrm{SnI}_{6}$ octahedra) and smaller Sn-I-Sn angles, and thus a larger bandgap than the (3AMPY) $\mathrm{Sn}_{2} \mathrm{I}_{6}$ structure.

Even though the M-I-M angles play a major role in determining the bandgap, we can also compare the local distortion of individual octahedra by looking at the distortion index (D), as defined above, to gain further insight on structure-property relationships. The structures with higher bandgaps tend to have larger local distortions. For example, $\mathrm{D}$ is larger for (4AMPY) $\mathrm{Sn}_{2} \mathrm{I}_{6}$, so 
(4AMPY)Sn ${ }_{2} \mathrm{I}_{6}$ has a higher bandgap than (3AMPY) $\mathrm{Sn}_{2} \mathrm{I}_{6}$ (Table 2). The $\mathrm{D}$ of the mixed 3AMPY/4AMPY compound falls between the two parent ones and so does the bandgap. But for structures with different connection motif, such as ( $3 \mathrm{AMPY}) \mathrm{Pb}_{2} \mathrm{I}_{6}$ and (4AMPY) $\mathrm{Pb}_{2} \mathrm{I}_{6}$, it is still the $\mathrm{Pb}-\mathrm{I}-\mathrm{Pb}$ angles that mainly determine the bandgap.

\section{Photoresponse}

Based on the promising optical and electronic properties of these materials, we carried out a preliminary assessment of the photoresponse by selecting crystals of the $(3 \mathrm{AMPY}) \mathrm{Pb}_{2} \mathrm{I}_{6}$ compound. Gallium and gold electrodes were applied on the $a b$ plane with the electric field along the $b$ direction, where all the octahedra are connected by corner-sharing. The (3AMPY)Pb $\mathrm{I}_{6}$ exhibits a high electrical resistivity of $6 \times 10^{8} \Omega \mathrm{cm}$ (Figure $\mathrm{S} 6 \mathrm{a}$ ), similar to $\mathrm{MAPbI}_{3} .{ }^{11,66}$ When exposed to ambient light, the device based on the $\mathrm{Ga} /(3 \mathrm{AMPY}) \mathrm{Pb}_{2} \mathrm{I}_{6} / \mathrm{Au}$ structure showed a clear photoresponse (Figure S6a). Because of the Schottky barrier formed by the work function difference of $\mathrm{Ga}$ and $\mathrm{Au}$, the device exhibits reversible on-off switching property under ambient light even without an external field (Figure S6b). The on-off photoresponse was also measured under $2 \mathrm{~V}$ bias resulting in higher photocurrent (Figure 8a). Photoconductivity measurements on the device carried out under a $10 \mathrm{~mW} / \mathrm{cm}^{2}$ lamp indicate a pronounced photoresponse with a 10 times higher photocurrent than the dark current (Figure 8b). These results suggest great potential for photo detection applications at room temperature.

Because of the high density $\left(4.06 \mathrm{~g} / \mathrm{cm}^{3}\right)$ and the presence of heavy Pb element, the ( $3 \mathrm{AMPY} \mathrm{Pb}_{2} \mathrm{I}_{6}$ has a high X-ray absorption coefficient and a prominent X-ray detection response. Figure $8 \mathrm{c}$ shows the X-ray photocurrent of the (3AMPY) $\mathrm{Pb}_{2} \mathrm{I}_{6}$ device using the uncollimated $\mathrm{Ag} \mathrm{X}$-ray tube with a dose rate of $259.1 \mu \mathrm{Gy} / \mathrm{s}$ and a peak voltage of $50 \mathrm{kV}$. The product of charge carrier mobility $(\mu)$ and carrier lifetime $(\tau)$ is a figure of merit used to evaluate the effectiveness of X-ray radiation detectors and can be obtained from the I-V data using the Many equation ${ }^{67-68}$ (eq (3)), where $\mathrm{I}_{0}$ is the saturated photocurrent, $\mathrm{V}$ is the applied bias and $\mathrm{L}$ is the thickness.

$$
I=\frac{I_{0} \mu \tau V 1-\exp \left(-\frac{L^{2}}{\mu \tau V}\right)}{L^{2}}
$$

The fitting in Figure 8c for the (3AMPY)Pb ${ }_{2} \mathrm{I}_{6}$ device yields a $\mu \tau$ product of $1.2 \times 10^{-4} \mathrm{~cm}^{2} / \mathrm{V}$, which is similar to the value reported for $\mathrm{MAPbI}_{3} .{ }^{11}$ This is an impressive $\mu \tau$ value and shows a promising 
charge collection performance for X-ray detection applications. The X-ray sensitivity was also determined by measuring the $\mathrm{X}$-ray response under different radiation dose rates (Figure $\mathrm{S} 7$ ). The $\mathrm{X}$-ray dose was controlled by varying the $\mathrm{Ag} \mathrm{X}$-ray tube current from $10 \mu \mathrm{A}$ to $60 \mu \mathrm{A}$ and was measured by a dosimeter. The photocurrent density of the ( $3 \mathrm{AMPY}) \mathrm{Pb}_{2} \mathrm{I}_{6}$ device increases with $\mathrm{X}$-ray dose rate and follows a linear relationship which is consistent with a well behaved semiconductor (Figure 8d). The extracted X-ray sensitivity of the device is high at $207 \mu \mathrm{C} \cdot \mathrm{Gy}^{-}$ ${ }^{1} \cdot \mathrm{cm}^{-2}$. This value is comparable to the state-of-art commercialized materials $\mathrm{Cd}_{1-\mathrm{x}} \mathrm{Zn}_{\mathrm{x}} \mathrm{Te}(\mathrm{CZT})$ $\left(318 \mu \mathrm{C} \cdot \mathrm{Gy}^{-1} \cdot \mathrm{cm}^{-2}\right)$ and $\alpha$-Se $\left(20 \mu \mathrm{C} \cdot \mathrm{Gy}^{-1} \cdot \mathrm{cm}^{-2}\right) \cdot{ }^{69} \mathrm{Here}$, we only report preliminary results of $\mathrm{X}$ ray detection as we believe the material can achieve better performance after optimization of crystal quality, size, device structure and controlled orientation within a device for full utilization of the charge mobilities.

\section{Conclusions}

The organic di-cations xAMPY $(x=3,4)$ template two new types of 3D halide networks in (xAMPY) $\mathrm{Sn}_{2} \mathrm{I}_{6}$ and (xAMPY) $\mathrm{Pb}_{2} \mathrm{I}_{6}$. Their structures feature a combination of corner-sharing and edge-sharing octahedra. Because of the multiple modes of linking of the $\mathrm{MI}_{6}$ octahedra, these compounds are not proper perovskites and belong to the broader class of so-called perovskitoids. The bandgaps of the $\mathrm{Sn}$ and $\mathrm{Pb}$ compounds are $\sim 1.7 \mathrm{eV}$ and $\sim 2.0 \mathrm{eV}$, respectively. DFT calculations indicate that these compounds are indirect bandgap semiconductors but with additional direct bandgaps at slightly higher energies and band structures that resemble those of the $\mathrm{AMI}_{3}$ perovskites. The band structures are anisotropic and exhibit large electronic band dispersions and low effective electron masses, especially along the direction in which all octahedra are corner-shared, with the $\mathrm{Sn}$ analogs having broader bands. The lattices seem to undergo local polar fluctuations with crystal-liquid lattice dynamics as suggested by the Raman scattering experiments. This is expected to result in large polaron formation in these materials and good screening of charge carriers, leading to defect tolerance, similar to 3D perovskites. Indeed, these special characteristics and the favorable electronic structure of the compounds lead to large photoresponse under ambient light even without an applied bias. (3AMPY) $\mathrm{Pb}_{2} \mathrm{I}_{6}$ crystals also show excellent response under Ag X-ray irradiation, with a high carrier mobility and lifetime product $(\mu \tau)$ of $1.2 \times 10^{-4} \mathrm{~cm}^{2} / \mathrm{V}$ and an X-ray sensitivity of $207 \mu \mathrm{C} \cdot \mathrm{Gy}^{-1} \cdot \mathrm{cm}^{-2}$. 


\section{Associated Content}

\section{Supporting information}

Additional experimental details for powder X-ray diffraction, absorption spectroscopy, Raman spectroscopy, crystallographic details, experimental and calculated PXRD patterns, and optoelectronic properties.

X-ray crystallographic data of (3AMPY) $\mathrm{Pb}_{2} \mathrm{I}_{6}$. $\mathrm{X}$-ray crystallographic data of (4AMPY) $\mathrm{Pb}_{2} \mathrm{I}_{6}$. X-ray crystallographic data of (3AMPY) $\mathrm{Sn}_{2} \mathrm{I}_{6}$. X-ray crystallographic data of (4AMPY) $\mathrm{Sn}_{2} \mathrm{I}_{6}$. $\mathrm{X}$-ray crystallographic data of (3AMPY)PbSnI 6 . X-ray crystallographic data of (3AMPY $)_{0.5}(4 \mathrm{AMPY})_{0.5} \mathrm{Sn}_{2} \mathrm{I}_{6}$.

\section{Author information}

\section{Corresponding Author}

*m-kanatzidis@,northwestern.edu

\section{Notes}

The authors declare no competing financial interest.

\section{Acknowledgements}

At Northwestern University this work is mainly supported by the Department of Energy, Office of Science, Basic Energy Sciences, under Grant No. SC0012541 (synthesis, structure, and physical property characterization). DFT calculations were performed at the Institut des Sciences Chimiques de Rennes, which received funding from the Agence Nationale pour la Recherche (TRANSHYPERO project) and the work was granted access to the HPC resources of TGCC/CINES/IDRIS under the allocation 2018-A0010907682 made by GENCI. M. K. acknowledges support from Region Bretagne through Boost'ERC LaHPerOS project. J.E acknowledges the financial support from the Institut Universitaire de France. Raman measurements were performed at GeoSoilEnviroCARS (The University of Chicago, Sector 13), Advanced Photon Source (APS), Argonne National Laboratory. GeoSoilEnviroCARS is supported by the National Science Foundation - Earth Sciences (EAR - 1634415). The Raman system 
acquisition was supported by the NSF MRI proposal (EAR-1531583). This work was performed, in part, at the Center for Nanoscale Materials, a U.S. Department of Energy Office of Science User Facility, and supported by the U.S. Department of Energy, Office of Science, under Contract No. DE-AC02-06CH11357. This work made use of the SPID (confocal microscopy) facilities of Northwestern University's NUANCE Center, which has received support from the Soft and Hybrid Nanotechnology Experimental Resource (NSF ECCS1542205), the Materials Research Science and Engineering Centers (NSF DMR-1720139), the International Institute for Nanotechnology (IIN), the Keck Foundation, and the State of Illinois through the IIN. 


\section{References}

1. Tsai, H.; Asadpour, R.; Blancon, J.-C.; Stoumpos, C. C.; Durand, O.; Strzalka, J. W.; Chen, B.; Verduzco, R.; Ajayan, P. M.; Tretiak, S.; Even, J.; Alam, M. A.; Kanatzidis, M. G.; Nie, W.; Mohite, A. D., Light-induced lattice expansion leads to high-efficiency perovskite solar cells. Science 2018, 360 (6384), 67-70.

2. Yang, W. S.; Park, B.-W.; Jung, E. H.; Jeon, N. J.; Kim, Y. C.; Lee, D. U.; Shin, S. S.; Seo, J.; Kim, E. K.; Noh, J. H.; Seok, S. I., Iodide management in formamidinium-lead-halide-based perovskite layers for efficient solar cells. Science 2017, 356 (6345), 1376-1379.

3. Arora, N.; Dar, M. I.; Hinderhofer, A.; Pellet, N.; Schreiber, F.; Zakeeruddin, S. M.; Grätzel, M., Perovskite solar cells with $\mathrm{CuSCN}$ hole extraction layers yield stabilized efficiencies greater than 20\%. Science 2017, 358 (6364), 768-771.

4. Dong, Q.; Fang, Y.; Shao, Y.; Mulligan, P.; Qiu, J.; Cao, L.; Huang, J., Electron-hole diffusion lengths $>175 \mu \mathrm{m}$ in solution-grown $\mathrm{CH}_{3} \mathrm{NH}_{3} \mathrm{PbI}_{3}$ single crystals. Science 2015, 347 (6225), 967-970.

5. Stoumpos, C. C.; Kanatzidis, M. G., The Renaissance of Halide Perovskites and Their Evolution as Emerging Semiconductors. Acc. Chem. Res. 2015, 48 (10), 2791-2802.

6. Stoumpos, C. C.; Kanatzidis, M. G., Halide Perovskites: Poor Man's High-Performance Semiconductors. Adv. Mater. 2016, 28 (28), 5778-5793.

7. $\quad$ Fang, Y.; Dong, Q.; Shao, Y.; Yuan, Y.; Huang, J., Highly narrowband perovskite singlecrystal photodetectors enabled by surface-charge recombination. Nat. Photonics 2015, 9, 679.

8. Wei, H.; Fang, Y.; Mulligan, P.; Chuirazzi, W.; Fang, H.-H.; Wang, C.; Ecker, B. R.; Gao, Y.; Loi, M. A.; Cao, L.; Huang, J., Sensitive X-ray detectors made of methylammonium lead tribromide perovskite single crystals. Nat. Photonics 2016, 10, 333.

9. Wei, H.; DeSantis, D.; Wei, W.; Deng, Y.; Guo, D.; Savenije, T. J.; Cao, L.; Huang, J., Dopant compensation in alloyed $\mathrm{CH}_{3} \mathrm{NH}_{3} \mathrm{PbBr}_{3-\mathrm{x}} \mathrm{Cl}_{\mathrm{x}}$ perovskite single crystals for gamma-ray spectroscopy. Nat. Mater. 2017, 16, 826.

10. He, Y.; Matei, L.; Jung, H. J.; McCall, K. M.; Chen, M.; Stoumpos, C. C.; Liu, Z.; Peters, J. A.; Chung, D. Y.; Wessels, B. W.; Wasielewski, M. R.; Dravid, V. P.; Burger, A.; Kanatzidis, M. G., High spectral resolution of gamma-rays at room temperature by perovskite $\mathrm{CsPbBr}_{3}$ single crystals. Nat. Commun. 2018, 9 (1), 1609.

11. He, Y.; Ke, W.; Alexander, G. C. B.; McCall, K. M.; Chica, D. G.; Liu, Z.; Hadar, I.; Stoumpos, C. C.; Wessels, B. W.; Kanatzidis, M. G., Resolving the Energy of $\gamma$-Ray Photons with $\mathrm{MAPbI}_{3}$ Single Crystals. ACS Photonics 2018, 5 (10), 4132-4138.

12. Pan, W.; Wu, H.; Luo, J.; Deng, Z.; Ge, C.; Chen, C.; Jiang, X.; Yin, W.-J.; Niu, G.; Zhu, L.; Yin, L.; Zhou, Y.; Xie, Q.; Ke, X.; Sui, M.; Tang, J., $\mathrm{Cs}_{2} \mathrm{AgBiBr}_{6}$ single-crystal X-ray detectors with a low detection limit. Nat. Photonics 2017, 11 (11), 726-732.

13. Yin, L.; Wu, H.; Pan, W.; Yang, B.; Li, P.; Luo, J.; Niu, G.; Tang, J., Controlled Cooling for Synthesis of $\mathrm{Cs}_{2} \mathrm{AgBiBr}_{6}$ Single Crystals and Its Application for X-Ray Detection. Advanced Optical Materials 2019, 7 (19), 1900491.

14. Yang, B.; Pan, W.; Wu, H.; Niu, G.; Yuan, J.-H.; Xue, K.-H.; Yin, L.; Du, X.; Miao, X.S.; Yang, X.; Xie, Q.; Tang, J., Heteroepitaxial passivation of $\mathrm{Cs}_{2} \mathrm{AgBiBr}_{6}$ wafers with suppressed ionic migration for X-ray imaging. Nat. Commun. 2019, 10 (1), 1989.

15. Xu, Z.; Liu, X.; Li, Y.; Liu, X.; Yang, T.; Ji, C.; Han, S.; Xu, Y.; Luo, J.; Sun, Z., Exploring Lead-Free Hybrid Double Perovskite Crystals of $(\mathrm{BA})_{2} \mathrm{CsAgBiBr}_{7}$ with Large Mobility-Lifetime Product toward X-Ray Detection. Angew. Chem., Int. Ed. 2019, 58 (44), 15757-15761. 
16. Zhuang, R.; Wang, X.; Ma, W.; Wu, Y.; Chen, X.; Tang, L.; Zhu, H.; Liu, J.; Wu, L.; Zhou, W.; Liu, X.; Yang, Y., Highly sensitive X-ray detector made of layered perovskite-like $\left(\mathrm{NH}_{4}\right)_{3} \mathrm{Bi}_{2} \mathrm{I}_{9}$ single crystal with anisotropic response. Nat. Photonics 2019, 13 (9), 602-608.

17. Liu, Y.; Zhang, Y.; Yang, Z.; Ye, H.; Feng, J.; Xu, Z.; Zhang, X.; Munir, R.; Liu, J.; Zuo, P.; Li, Q.; Hu, M.; Meng, L.; Wang, K.; Smilgies, D.-M.; Zhao, G.; Xu, H.; Yang, Z.; Amassian, A.; Li, J.; Zhao, K.; Liu, S., Multi-inch single-crystalline perovskite membrane for high-detectivity flexible photosensors. Nat. Commun. 2018, 9 (1), 5302.

18. Sun, Q.; Xu, Y.; Zhang, H.; Xiao, B.; Liu, X.; Dong, J.; Cheng, Y.; Zhang, B.; Jie, W.; Kanatzidis, M. G., Optical and electronic anisotropies in perovskitoid crystals of $\mathrm{Cs}_{3} \mathrm{Bi}_{2} \mathrm{I}_{9} \mathrm{studies}$ of nuclear radiation detection. J. Mater. Chem. A 2018, 6 (46), 23388-23395.

19. Wang, J.; Li, J.; Lan, S.; Fang, C.; Shen, H.; Xiong, Q.; Li, D., Controllable Growth of Centimeter-Sized 2D Perovskite Heterostructures for Highly Narrow Dual-Band Photodetectors. ACS Nano 2019, 13 (5), 5473-5484.

20. Ji, C.; Wang, S.; Wang, Y.; Chen, H.; Li, L.; Sun, Z.; Sui, Y.; Wang, S.; Luo, J., 2D Hybrid Perovskite Ferroelectric Enables Highly Sensitive X-Ray Detection with Low Driving Voltage. Adv. Funct. Mater. 2019, n/a (n/a), 1905529.

21. Umari, P.; Mosconi, E.; De Angelis, F., Relativistic GW calculations on $\mathrm{CH}_{3} \mathrm{NH}_{3} \mathrm{PbI}_{3}$ and $\mathrm{CH}_{3} \mathrm{NH}_{3} \mathrm{SnI}_{3}$ Perovskites for Solar Cell Applications. Sci. Rep. 2014, 4, 4467.

22. Even, J.; Pedesseau, L.; Katan, C., Analysis of Multivalley and Multibandgap Absorption and Enhancement of Free Carriers Related to Exciton Screening in Hybrid Perovskites. J. Phys. Chem. C 2014, 118 (22), 11566-11572.

23. Kamminga, M. E.; de Wijs, G. A.; Havenith, R. W. A.; Blake, G. R.; Palstra, T. T. M., The Role of Connectivity on Electronic Properties of Lead Iodide Perovskite-Derived Compounds. Inorg. Chem. 2017, 56 (14), 8408-8414.

24. Mao, L.; Guo, P.; Kepenekian, M.; Hadar, I.; Katan, C.; Even, J.; Schaller, R. D.; Stoumpos, C. C.; Kanatzidis, M. G., Structural Diversity in White-Light-Emitting Hybrid Lead Bromide Perovskites. J. Am. Chem. Soc. 2018, 140 (40), 13078-13088.

25. Hoffman, J. M.; Che, X.; Sidhik, S.; Li, X.; Hadar, I.; Blancon, J.-C.; Yamaguchi, H.; Kepenekian, M.; Katan, C.; Even, J.; Stoumpos, C. C.; Mohite, A. D.; Kanatzidis, M. G., From 2D to 1D Electronic Dimensionality in Halide Perovskites with Stepped and Flat Layers Using Propylammonium as a Spacer. J. Am. Chem. Soc. 2019, 141 (27), 10661-10676.

26. Kieslich, G.; Sun, S.; Cheetham, A. K., Solid-state principles applied to organic-inorganic perovskites: new tricks for an old dog. Chem. Sci. 2014, 5 (12), 4712-4715.

27. Ke, W.; Stoumpos, C. C.; Zhu, M.; Mao, L.; Spanopoulos, I.; Liu, J.; Kontsevoi, O. Y.; Chen, M.; Sarma, D.; Zhang, Y.; Wasielewski, M. R.; Kanatzidis, M. G., Enhanced photovoltaic performance and stability with a new type of hollow 3D perovskite (en)FASnI $3 . S c i . A d v .2017,3$ (8), e1701293.

28. Spanopoulos, I.; Ke, W.; Stoumpos, C. C.; Schueller, E. C.; Kontsevoi, O. Y.; Seshadri, R.; Kanatzidis, M. G., Unraveling the Chemical Nature of the 3D "Hollow" Hybrid Halide Perovskites. J. Am. Chem. Soc. 2018, 140 (17), 5728-5742.

29. Leblanc, A.; Mercier, N.; Allain, M.; Dittmer, J.; Pauporté, T.; Fernandez, V.; Boucher, F.; Kepenekian, M.; Katan, C., Enhanced Stability and Band Gap Tuning of $\alpha-\left[\mathrm{HC}\left(\mathrm{NH}_{2}\right)_{2}\right] \mathrm{PbI}_{3}$ Hybrid Perovskite by Large Cation Integration. ACS Appl. Mater. Interfaces 2019, 11 (23), 2074320751. 
30. Leblanc, A.; Mercier, N.; Allain, M.; Dittmer, J.; Fernandez, V.; Pauporté, T., Lead- and Iodide-Deficient $\left(\mathrm{CH}_{3} \mathrm{NH}_{3}\right) \mathrm{PbI}_{3}$ (d-MAPI): The Bridge between 2D and 3D Hybrid Perovskites. Angew. Chem., Int. Ed. 2017, 56 (50), 16067-16072.

31. Mao, L.; Stoumpos, C. C.; Kanatzidis, M. G., Two-Dimensional Hybrid Halide Perovskites: Principles and Promises. J. Am. Chem. Soc. 2019, 141 (3), 1171-1190.

32. Li, X.; Guo, P.; Kepenekian, M.; Hadar, I.; Katan, C.; Even, J.; Stoumpos, C. C.; Schaller, R. D.; Kanatzidis, M. G., Small Cyclic Diammonium Cation Templated (110)-Oriented 2D Halide $(\mathrm{X}=\mathrm{I}, \mathrm{Br}, \mathrm{Cl}$ ) Perovskites with White-Light Emission. Chem. Mater. 2019, 31 (9), 3582-3590.

33. Ben Haj Salah, M.; Mercier, N.; Allain, M.; Zouari, N.; Botta, C., Dual phosphorescence from the organic and inorganic moieties of $1 \mathrm{D}$ hybrid perovskites of the $\mathrm{Pb}_{\mathrm{n}^{\prime}} \mathrm{Br}_{4 \mathrm{n}^{\prime}+2}$ series $\left(\mathrm{n}^{\prime}=2\right.$, 3, 4, 5). J. Mater. Chem. C 2019, 7 (15), 4424-4433.

34. Katan, C.; Mercier, N.; Even, J., Quantum and Dielectric Confinement Effects in LowerDimensional Hybrid Perovskite Semiconductors. Chem. Rev. 2019, 119 (5), 3140-3192.

35. Li, X.; Hoffman, J.; Ke, W.; Chen, M.; Tsai, H.; Nie, W.; Mohite, A. D.; Kepenekian, M.; Katan, C.; Even, J.; Wasielewski, M. R.; Stoumpos, C. C.; Kanatzidis, M. G., Two-Dimensional Halide Perovskites Incorporating Straight Chain Symmetric Diammonium Ions, $\left(\mathrm{NH}_{3} \mathrm{C}_{\mathrm{m}} \mathrm{H}_{2 \mathrm{~m}} \mathrm{NH}_{3}\right)\left(\mathrm{CH}_{3} \mathrm{NH}_{3}\right)_{\mathrm{n}-1} \mathrm{~Pb}_{\mathrm{n}} \mathrm{I}_{3 \mathrm{n}+1}(\mathrm{~m}=4-9 ; \mathrm{n}=1-4)$. J. Am. Chem. Soc. 2018, 140 (38), 12226-12238.

36. Mao, L.; Ke, W.; Pedesseau, L.; Wu, Y.; Katan, C.; Even, J.; Wasielewski, M. R.; Stoumpos, C. C.; Kanatzidis, M. G., Hybrid Dion-Jacobson 2D Lead Iodide Perovskites. J. Am. Chem. Soc. 2018, 140 (10), 3775-3783.

37. Li, Y.; Zheng, G.; Lin, C.; Lin, J., Synthesis, structure and optical properties of different dimensional organic-inorganic perovskites. Solid State Sci. 2007, 9 (9), 855-861.

38. Yu, H.; Wei, Z.; Hao, Y.; Liang, Z.; Fu, Z.; Cai, H., Reversible solid-state thermochromism of a 2D organic-inorganic hybrid perovskite structure based on iodoplumbate and 2-aminomethylpyridine. New J. Chem. 2017, 41 (18), 9586-9589.

39. Lermer, C.; Senocrate, A.; Moudrakovski, I.; Seewald, T.; Hatz, A.-K.; Mayer, P.; Pielnhofer, F.; Jaser, J. A.; Schmidt-Mende, L.; Maier, J.; Lotsch, B. V., Completing the Picture of 2-(Aminomethylpyridinium) Lead Hybrid Perovskites: Insights into Structure, Conductivity Behavior, and Optical Properties. Chem. Mater. 2018, 30 (18), 6289-6297.

40. Li, X.; Ke, W.; Traoré, B.; Guo, P.; Hadar, I.; Kepenekian, M.; Even, J.; Katan, C.; Stoumpos, C. C.; Schaller, R. D.; Kanatzidis, M. G., Two-Dimensional Dion-Jacobson Hybrid Lead Iodide Perovskites with Aromatic Diammonium Cations. J. Am. Chem. Soc. 2019, 141 (32), 12880-12890.

41. Stoumpos, C. C.; Mao, L.; Malliakas, C. D.; Kanatzidis, M. G., Structure-Band Gap Relationships in Hexagonal Polytypes and Low-Dimensional Structures of Hybrid Tin Iodide Perovskites. Inorg. Chem. 2017, 56 (1), 56-73.

42. Petříček, V.; Dušek, M.; Palatinus, L., Crystallographic Computing System JANA2006: General features. Z. Kristallogr. - Cryst. Mater. 2014, 229 (5), 345.

43. Spek, A., Structure validation in chemical crystallography. Acta Crystallogr. D 2009, 65 (2), 148-155.

44. Artacho, E.; Anglada, E.; Diéguez, O.; Gale, J. D.; García, A.; Junquera, J.; Martin, R. M.; Ordejón, P.; Pruneda, J. M.; Sánchez-Portal, D.; Soler, J. M., The SIESTA method; developments and applicability. J. Phys.: Condens. Matter 2008, 20 (6), 064208. 
45. Soler, J. M.; Artacho, E.; Gale, J. D.; García, A.; Junquera, J.; Ordejón, P.; Sánchez-Portal, D., The SIESTA method for ab initio order- N materials simulation. J. Phys.: Condens. Matter 2002, 14 (11), 2745.

46. Zhang, Y.; Yang, W., Comment on "Generalized Gradient Approximation Made Simple". Phys. Rev. Lett. 1998, 80 (4), 890-890.

47. Troullier, N.; Martins, J. L., Efficient pseudopotentials for plane-wave calculations. Phys. Rev. B 1991, 43 (3), 1993-2006.

48. Artacho, E.; Sánchez-Portal, D.; Ordejón, P.; García, A.; Soler, J. M., Linear-Scaling abinitio Calculations for Large and Complex Systems. Phys. Status Solidi B 1999, 215 (1), 809-817.

49. Fernández-Seivane, L.; Oliveira, M. A.; Sanvito, S.; Ferrer, J., On-site approximation for spin-orbit coupling in linear combination of atomic orbitals density functional methods. J. Phys.: Condens. Matter 2006, 18 (34), 7999.

50. Stoumpos, C. C.; Cao, D. H.; Clark, D. J.; Young, J.; Rondinelli, J. M.; Jang, J. I.; Hupp, J. T.; Kanatzidis, M. G., Ruddlesden-Popper Hybrid Lead Iodide Perovskite 2D Homologous Semiconductors. Chem. Mater. 2016, 28 (8), 2852-2867.

51. Robinson, K.; Gibbs, G. V.; Ribbe, P. H., Quadratic Elongation: A Quantitative Measure of Distortion in Coordination Polyhedra. Science 1971, 172 (3983), 567-570.

52. Momma, K.; Izumi, F., VESTA 3 for three-dimensional visualization of crystal, volumetric and morphology data. J. Appl. Cryst. 2011, 44 (6), 1272-1276.

53. Chelikowsky, J.; Chadi, D. J.; Cohen, M. L., Calculated Valence-Band Densities of States and Photoemission Spectra of Diamond and Zinc-Blende Semiconductors. Phys. Rev. B 1973, 8 (6), 2786-2794.

54. Fabini, D. H.; Laurita, G.; Bechtel, J. S.; Stoumpos, C. C.; Evans, H. A.; Kontos, A. G.; Raptis, Y. S.; Falaras, P.; Van der Ven, A.; Kanatzidis, M. G.; Seshadri, R., Dynamic Stereochemical Activity of the $\mathrm{Sn}^{2+}$ Lone Pair in Perovskite $\mathrm{CsSnBr}_{3}$. J. Am. Chem. Soc. 2016, 138 (36), 11820-11832.

55. Quarti, C.; Grancini, G.; Mosconi, E.; Bruno, P.; Ball, J. M.; Lee, M. M.; Snaith, H. J.; Petrozza, A.; De Angelis, F., The Raman Spectrum of the $\mathrm{CH}_{3} \mathrm{NH}_{3} \mathrm{PbI}_{3}$ Hybrid Perovskite: Interplay of Theory and Experiment. J. Phys. Chem. Lett. 2014, 5 (2), 279-284.

56. Zhu, H.; Miyata, K.; Fu, Y.; Wang, J.; Joshi, P. P.; Niesner, D.; Williams, K. W.; Jin, S.; Zhu, X.-Y., Screening in crystalline liquids protects energetic carriers in hybrid perovskites. Science 2016, 353 (6306), 1409-1413.

57. Miyata, K.; Atallah, T. L.; Zhu, X.-Y., Lead halide perovskites: Crystal-liquid duality, phonon glass electron crystals, and large polaron formation. Sci. Adv. 2017, 3 (10), e1701469.

58. Yaffe, O.; Guo, Y.; Tan, L. Z.; Egger, D. A.; Hull, T.; Stoumpos, C. C.; Zheng, F.; Heinz, T. F.; Kronik, L.; Kanatzidis, M. G.; Owen, J. S.; Rappe, A. M.; Pimenta, M. A.; Brus, L. E., Local Polar Fluctuations in Lead Halide Perovskite Crystals. Phys. Rev. Lett. 2017, 118 (13), 136001.

59. Huang, L.-y.; Lambrecht, W. R. L., Electronic band structure, phonons, and exciton binding energies of halide perovskites $\mathrm{CsSnCl}_{3}, \mathrm{CsSnBr}_{3}$, and $\mathrm{CsSnI}_{3}$. Phys. Rev. B 2013, 88 (16), 165203.

60. Cao, D. H.; Stoumpos, C. C.; Yokoyama, T.; Logsdon, J. L.; Song, T.-B.; Farha, O. K.; Wasielewski, M. R.; Hupp, J. T.; Kanatzidis, M. G., Thin Films and Solar Cells Based on Semiconducting Two-Dimensional Ruddlesden-Popper $\left(\mathrm{CH}_{3}\left(\mathrm{CH}_{2}\right)_{3} \mathrm{NH}_{3}\right)_{2}\left(\mathrm{CH}_{3} \mathrm{NH}_{3}\right)_{\mathrm{n}-1} \mathrm{Sn}_{\mathrm{n}} \mathrm{I}_{3 \mathrm{n}+1}$ Perovskites. ACS Energy Lett. 2017, 2 (5), 982-990. 
61. Wang, C.; Song, Z.; Li, C.; Zhao, D.; Yan, Y., Low-Bandgap Mixed Tin-Lead Perovskites and Their Applications in All-Perovskite Tandem Solar Cells. Adv. Funct. Mater. 2019, 0 (0), 1808801.

62. Goyal, A.; McKechnie, S.; Pashov, D.; Tumas, W.; van Schilfgaarde, M.; Stevanović, V., Origin of Pronounced Nonlinear Band Gap Behavior in Lead-Tin Hybrid Perovskite Alloys. Chem. Mater. 2018, 30 (11), 3920-3928.

63. Hao, F.; Stoumpos, C. C.; Chang, R. P. H.; Kanatzidis, M. G., Anomalous Band Gap Behavior in Mixed $\mathrm{Sn}$ and $\mathrm{Pb}$ Perovskites Enables Broadening of Absorption Spectrum in Solar Cells. J. Am. Chem. Soc. 2014, 136 (22), 8094-8099.

64. Mao, L.; Tsai, H.; Nie, W.; Ma, L.; Im, J.; Stoumpos, C. C.; Malliakas, C. D.; Hao, F.; Wasielewski, M. R.; Mohite, A. D.; Kanatzidis, M. G., Role of Organic Counterion in Lead- and Tin-Based Two-Dimensional Semiconducting Iodide Perovskites and Application in Planar Solar Cells. Chem. Mater. 2016, 28 (21), 7781-7792.

65. Knutson, J. L.; Martin, J. D.; Mitzi, D. B., Tuning the Band Gap in Hybrid Tin Iodide Perovskite Semiconductors Using Structural Templating. Inorg. Chem. 2005, 44 (13), 4699-4705. 66. Stoumpos, C. C.; Malliakas, C. D.; Kanatzidis, M. G., Semiconducting Tin and Lead Iodide Perovskites with Organic Cations: Phase Transitions, High Mobilities, and Near-Infrared Photoluminescent Properties. Inorg. Chem. 2013, 52 (15), 9019-9038.

67. Many, A., High-field effects in photoconducting cadmium sulphide. J. Phys. Chem. Solids 1965, $26(3), 575-578$.

68. Stoumpos, C. C.; Malliakas, C. D.; Peters, J. A.; Liu, Z.; Sebastian, M.; Im, J.; Chasapis, T. C.; Wibowo, A. C.; Chung, D. Y.; Freeman, A. J.; Wessels, B. W.; Kanatzidis, M. G., Crystal Growth of the Perovskite Semiconductor $\mathrm{CsPbBr}_{3}$ : A New Material for High-Energy Radiation Detection. Cryst. Growth Des. 2013, 13 (7), 2722-2727.

69. Wei, H.; Huang, J., Halide lead perovskites for ionizing radiation detection. Nat. Commun. 2019, 10 (1), 1066. 
Table 1. Crystal and Refinement Data for Compounds Reported Here

\begin{tabular}{|c|c|c|c|}
\hline Compound & $(3 \mathrm{AMPY}) \mathrm{Pb}_{2} \mathrm{I}_{6}$ & (3AMPY)PbSnI 6 & (4AMPY) $\mathrm{Pb}_{2} \mathrm{I}_{6}$ \\
\hline Empirical formula & C6 H10 I6 N2 Pb2 & $\begin{array}{l}\text { C6 H10 I6 N2 } \\
\text { Pb0.91 Sn1.09 }\end{array}$ & C6 H10 I6 N2 Pb2 \\
\hline Crystal system & monoclinic & monoclinic & monoclinic \\
\hline Space group & Im & $\operatorname{Im}$ & $I a$ \\
\hline Unit cell dimensions & $\begin{array}{l}a=16.3698(12) \AA \\
b=25.6376(16) \AA \\
c=10.0435(6) \AA \\
\beta=93.198(6)^{\circ}\end{array}$ & $\begin{array}{l}a=16.3397(12) \AA \\
b=25.5520(16) \AA \\
c=10.0204(6) \AA \\
\beta=93.130(6)^{\circ}\end{array}$ & $\begin{array}{l}a=25.696(5) \AA \\
b=10.153(2) \AA \\
c=16.283(3) \AA \\
\beta=90.036^{\circ}\end{array}$ \\
\hline Volume & $4208.5(5) \AA^{3}$ & $4177.4(5) \AA^{3}$ & $4248.0(14) \AA^{3}$ \\
\hline Density (calculated) & $4.0592 \mathrm{~g} / \mathrm{cm}^{3}$ & $3.7827 \mathrm{~g} / \mathrm{cm}^{3}$ & $4.0215 \mathrm{~g} / \mathrm{cm}^{3}$ \\
\hline Index ranges & $\begin{array}{l}-19<=\mathrm{h}<=22 \\
-35<=\mathrm{k}<=35 \\
-13<=\mathrm{k}<=13\end{array}$ & $\begin{array}{l}-22<=\mathrm{h}<=22 \\
-34<=\mathrm{k}<=34 \\
-13<=\mathrm{l}<=13\end{array}$ & $\begin{array}{l}-34<=\mathrm{h}<=35 \\
-13<=\mathrm{k}<=13 \\
-22<=1<=22\end{array}$ \\
\hline Independent reflections & $7376\left[\mathrm{R}_{\mathrm{int}}=0.0559\right]$ & $7371\left[\mathrm{R}_{\mathrm{int}}=0.0639\right]$ & $7292\left[\mathrm{R}_{\mathrm{int}}=0.0481\right]$ \\
\hline Completeness to $25^{\circ}$ & $99 \%$ & $99 \%$ & $99 \%$ \\
\hline $\begin{array}{l}\text { Data / restraints / } \\
\text { parameters }\end{array}$ & $7376 / 16 / 213$ & $7371 / 16 / 216$ & $7292 / 34 / 196$ \\
\hline Goodness-of-fit & 3.35 & 2.87 & 2.12 \\
\hline Final $R$ indices $[I>2 \sigma(I)]$ & $\begin{array}{l}\mathrm{R}_{\mathrm{obs}}=0.0542 \\
\mathrm{wR}_{\mathrm{obs}}=0.0595\end{array}$ & $\begin{array}{l}\mathrm{R}_{\mathrm{obs}}=0.0523 \\
\mathrm{wR}_{\mathrm{obs}}=0.0710\end{array}$ & $\begin{array}{l}\mathrm{R}_{\mathrm{obs}}=0.0393 \\
\mathrm{wR}_{\mathrm{obs}}=0.0401\end{array}$ \\
\hline Largest diff. peak and hole & 2.89 and $-5.19 \mathrm{e} \cdot \AA^{-3}$ & 2.05 and $-3.78 \mathrm{e} \cdot \AA^{-3}$ & 1.57 and $-1.07 \mathrm{e} \cdot \AA^{-3}$ \\
\hline Compound & $(3 \mathrm{AMPY}) \mathrm{Sn}_{2} \mathrm{I}_{6}$ & $(3 \mathrm{AMPY})_{0.5}(4 \mathrm{AMPY})_{0.5} \mathrm{Sn}_{2} \mathrm{I}_{6}$ & (4AMPY) $\mathrm{Sn}_{2} \mathrm{I}_{6}$ \\
\hline Empirical formula & C6 H10 I6 N2 Sn2 & C6 H10 I6 N2 Sn2 & C6 H10 I6 N2 Sn2 \\
\hline Crystal system & monoclinic & monoclinic & monoclinic \\
\hline Space group & Im & $\operatorname{Im}$ & Im \\
\hline Unit cell dimensions & $\begin{array}{l}a=16.2885(12) \AA \\
b=25.4252(16) \AA \\
c=9.9795(6) \AA \\
\beta=92.951(6)^{\circ}\end{array}$ & $\begin{array}{l}a=16.3185(12) \AA \\
b=25.4637(16) \AA \\
c=10.0068(6) \AA \\
\beta=92.490(6)^{\circ}\end{array}$ & $\begin{array}{l}a=16.2208(12) \AA \\
b=25.4537(16) \AA \\
c=10.0307(6) \\
\beta=91.466(6)^{\circ}\end{array}$ \\
\hline Volume & $4127.4(5) \AA^{3}$ & $4154.2(5) \AA^{3}$ & $4140.1(5) \AA^{3}$ \\
\hline Density (calculated) & $3.5694 \mathrm{~g} / \mathrm{cm}^{3}$ & $3.5464 \mathrm{~g} / \mathrm{cm}^{3}$ & $3.5585 \mathrm{~g} / \mathrm{cm}^{3}$ \\
\hline Index ranges & $\begin{array}{l}-22<=\mathrm{h}<=19 \\
-34<=\mathrm{k}<=34 \\
-13<=\mathrm{l}<=13\end{array}$ & $\begin{array}{l}-22<=\mathrm{h}<=22 \\
-34<=\mathrm{k}<=34 \\
-13<=1<=13\end{array}$ & $\begin{array}{c}-19<=\mathrm{h}<=22 \\
-34<=\mathrm{k}<=34 \\
-13<=\mathrm{l}<=13\end{array}$ \\
\hline Independent reflections & $7289\left[\mathrm{R}_{\mathrm{int}}=0.0384\right]$ & $7314\left[\mathrm{R}_{\mathrm{int}}=0.0565\right]$ & $7285\left[\mathrm{R}_{\mathrm{int}}=0.0406\right]$ \\
\hline Completeness to $25^{\circ}$ & $100 \%$ & $99 \%$ & $99 \%$ \\
\hline $\begin{array}{l}\text { Data / restraints / } \\
\text { parameters }\end{array}$ & $7289 / 18 / 214$ & $7314 / 16 / 214$ & $7285 / 18 / 213$ \\
\hline Goodness-of-fit & 1.34 & 4.34 & 3.14 \\
\hline Final $R$ indices $[I>2 \sigma(I)]$ & $\begin{array}{l}\mathrm{R}_{\mathrm{obs}}=0.0339 \\
\mathrm{wR}_{\mathrm{obs}}=0.0306\end{array}$ & $\begin{array}{l}\mathrm{R}_{\mathrm{obs}}=0.0557 \\
\mathrm{wR}_{\mathrm{obs}}=0.0939\end{array}$ & $\begin{array}{l}\mathrm{R}_{\mathrm{obs}}=0.0705 \\
\mathrm{wR}_{\mathrm{obs}}=0.0688\end{array}$ \\
\hline Largest diff. peak and hole & 1.30 and $-0.97 \mathrm{e} \cdot \AA^{-3}$ & 2.46 and $-3.69 \mathrm{e} \cdot \AA^{-3}$ & 3.60 and $-3.58 \mathrm{e} \cdot \AA^{-3}$ \\
\hline
\end{tabular}


Table 2. Average Equatorial M-I-M Angle, Average Axial M-I-M Angle, Average M-I-M Angle, Distortion Index (D), Bond Angle Variance $\left(\sigma^{2}\right)$ and Bandgap for Compounds Reported Here. (Angles are only associated with the corner-sharing octahedra, and those of the edge-sharing octahedra are not listed)

\begin{tabular}{cccccc}
\hline & $(3 \mathrm{AMPY}) \mathrm{Sn}_{2} \mathrm{I}_{6}$ & $\begin{array}{c}(3 \mathrm{AMPY})_{0.5} \\
(4 \mathrm{AMPY})_{0.5} \mathrm{Sn}_{2} \mathrm{I}_{6}\end{array}$ & $\left(4 \mathrm{AMPY} \mathrm{Sn}_{2} \mathrm{I}_{6}\right.$ & $\left(3 \mathrm{AMPY} \mathrm{Pb}_{2} \mathrm{I}_{6}\right.$ & $\left(4 \mathrm{AMPY} \mathrm{Pb}_{2} \mathrm{I}_{6}\right.$ \\
\hline $\begin{array}{c}\text { Average equatorial } \\
\text { M-I-M angle }\left(^{\circ}\right)\end{array}$ & 168.09 & 168.90 & 165.26 & 167.27 & 158.47 \\
\hline $\begin{array}{c}\text { Average axial } \\
\text { M-I-M angle }\left(^{\circ}\right)\end{array}$ & 172.72 & 172.25 & 167.66 & 171.70 & 173.40 \\
\hline $\begin{array}{c}\text { Average } \\
\text { M-I-M angle }\left(^{\circ}\right)\end{array}$ & 169.94 & 170.24 & 167.90 & 169.04 & 165.93 \\
\hline $\mathrm{D}$ & 0.0113 & 0.0114 & 0.0172 & 0.0103 & 0.0096 \\
\hline$\sigma^{2}$ & 16.7 & 18.3 & 35.5 & 16.5 & 9.5 \\
\hline Bandgap $(\mathrm{eV})$ & 1.72 & 1.77 & 1.79 & 2.05 & 2.12 \\
\hline
\end{tabular}

Table 3. Calculated Hole $\left(\mathrm{m}_{\mathrm{h}}\right)$ and Electron $\left(\mathrm{m}_{\mathrm{e}}\right)$ Effective Mass for Compounds Reported Here. $\left(\mathrm{m}_{\mathrm{h}}{ }^{\|}\right.$and $\mathrm{m}_{\mathrm{e}} \|$ represent the hole and electron effective masses parallel to the corner-sharing direction. $\mathrm{m}_{\mathrm{h}}{ }^{\perp}$ and $\mathrm{m}_{\mathrm{e}}{ }^{\perp}$ represent the hole and electron effective masses perpendicular to that direction. $\mathrm{m}_{\mathrm{h}}^{\perp} / \mathrm{m}_{\mathrm{h}} \|$ and $\mathrm{m}_{\mathrm{e}}^{\perp} / \mathrm{m}_{\mathrm{e}}$ " represent the ratio between the two directions.)

\begin{tabular}{|c|c|c|c|c|}
\hline & \multicolumn{2}{|c|}{ Sn } & \multicolumn{2}{|c|}{$\mathbf{P b}$} \\
\hline & 3AMPY & 4AMPY & 3AMPY & 4AMPY \\
\hline $\mathrm{m}_{\mathrm{h}}\left(\mathrm{m}_{0}\right)$ & -0.163 & -0.154 & -0.372 & -0.787 \\
\hline $\mathrm{m}_{\mathrm{e}}\left(\mathrm{m}_{0}\right)$ & 0.119 & 0.126 & 0.251 & 0.276 \\
\hline $\mathrm{m}_{\mathrm{h}} \|\left(\mathrm{m}_{0}\right)$ & -0.035 & -0.067 & -0.194 & -0.535 \\
\hline $\mathrm{m}_{\mathrm{h}}^{\perp}\left(\mathrm{m}_{0}\right)$ & -0.352 & -0.234 & -0.270 & -0.956 \\
\hline $\mathrm{m}_{\mathrm{h}}^{\perp} / \mathrm{m}_{\mathrm{h}}$ & 10.1 & 3.49 & 1.39 & 1.79 \\
\hline $\mathrm{m}_{\mathrm{e}}^{\|}\left(\mathrm{m}_{0}\right)$ & 0.016 & 0.017 & 0.027 & 0.066 \\
\hline $\mathrm{m}_{\mathrm{e}}^{\perp}\left(\mathrm{m}_{0}\right)$ & 0.332 & 0.344 & 0.762 & 0.564 \\
\hline $\mathrm{m}_{\mathrm{e}}^{\perp} / \mathrm{m}_{\mathrm{e}}^{\|}$ & 20.8 & 20.2 & 28.2 & 8.55 \\
\hline
\end{tabular}



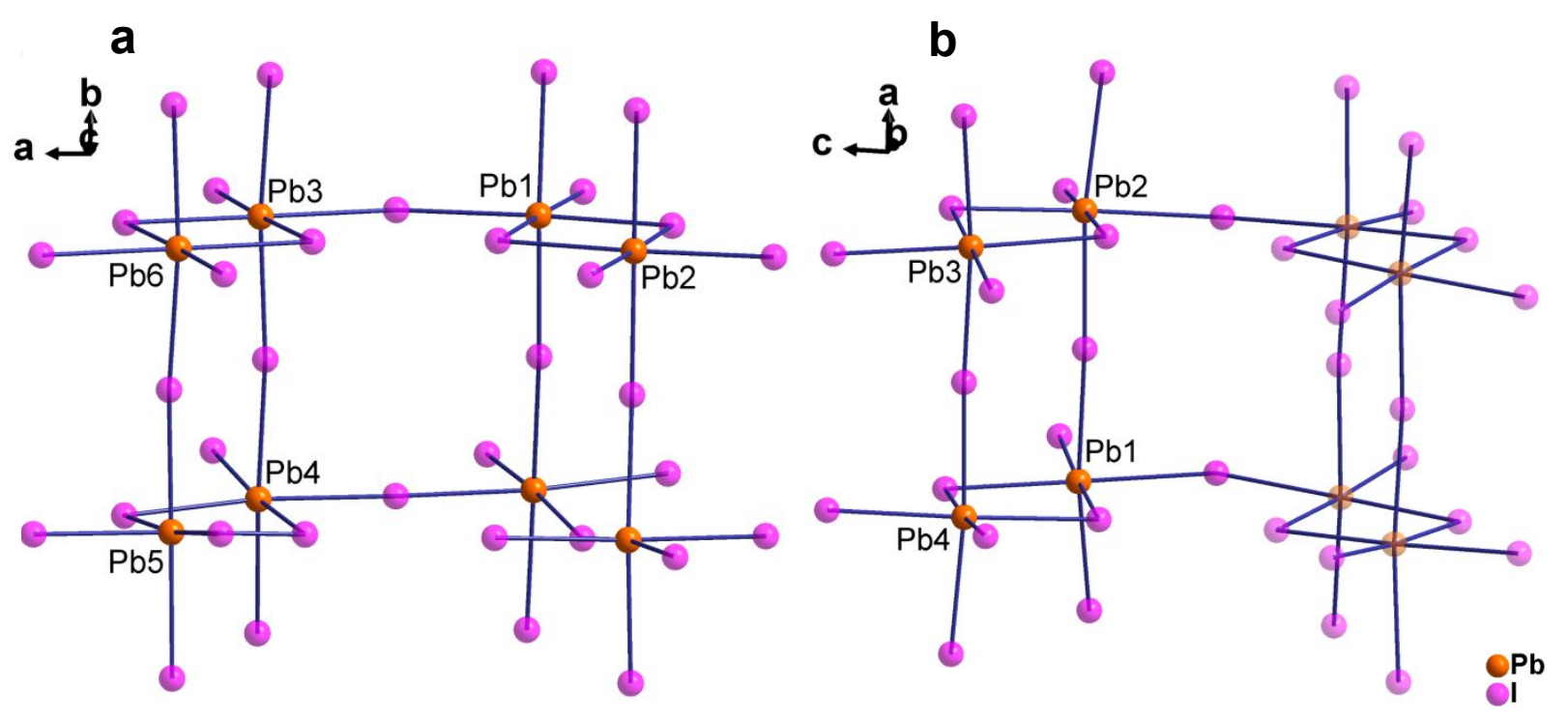

Figure 1. (a) Fragment of ( $4 \mathrm{AMPY}) \mathrm{Pb}_{2} \mathrm{I}_{6}$ structure. (b) Fragment of ( $\left.3 \mathrm{AMPY}\right) \mathrm{Pb}_{2} \mathrm{I}_{6}$ structure showing coordination environment and connectivity of octahedra. The structures feature a combination of linear corner-sharing linkages and bent edge-sharing ones. 

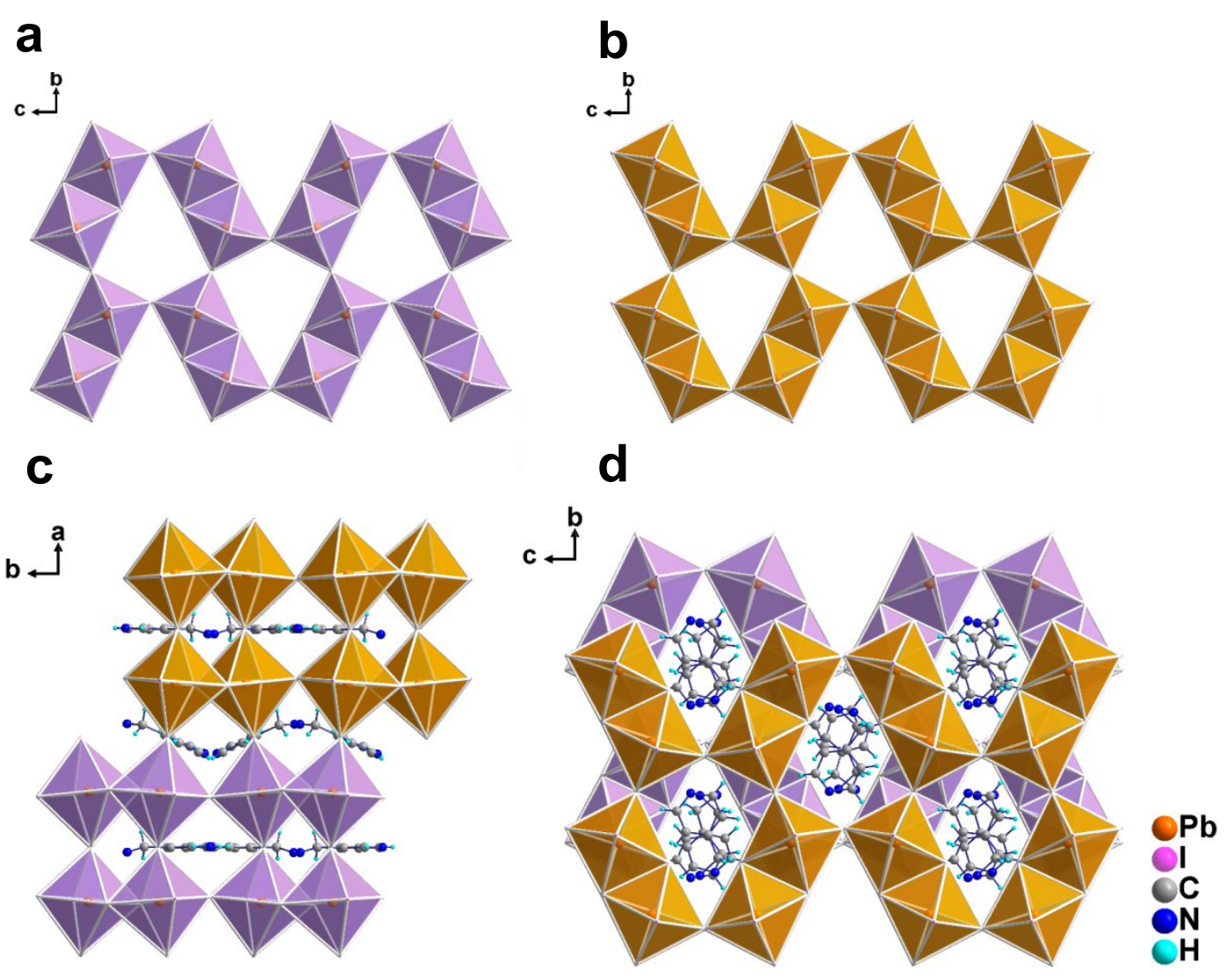

Figure 2. Crystal structures for (4AMPY) $\mathrm{Pb}_{2} \mathrm{I}_{6}$. (a) Connection motif of the octahedra for the bottom two layers. (b) Connection motif for the top two layers. They are symmetry-related by glide planes (organic cations omitted for clarity). (c) Crystal structure from side view. (d) Crystal structure from top view. The colors indicate the layers shown in (a) and (b). 


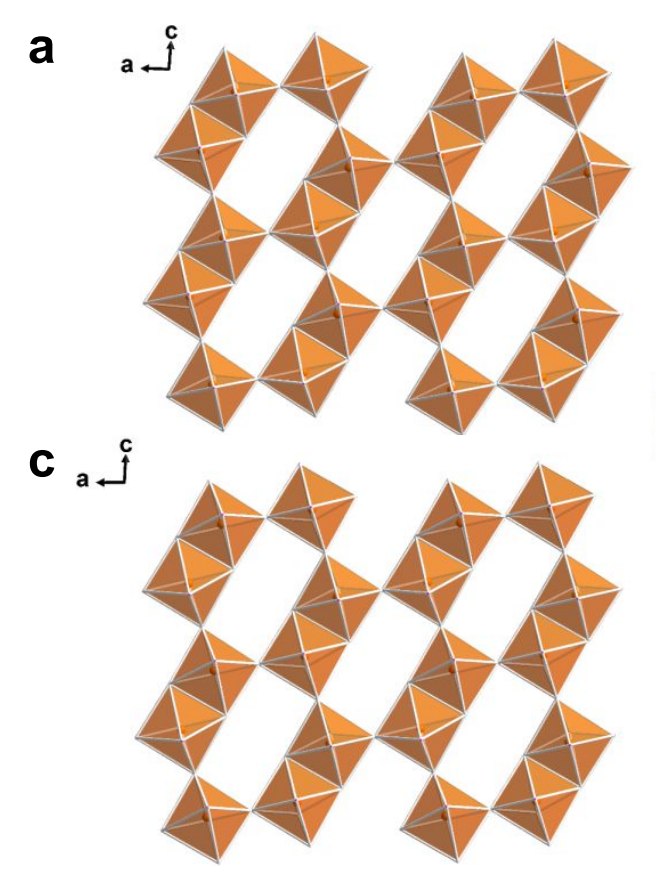

b.

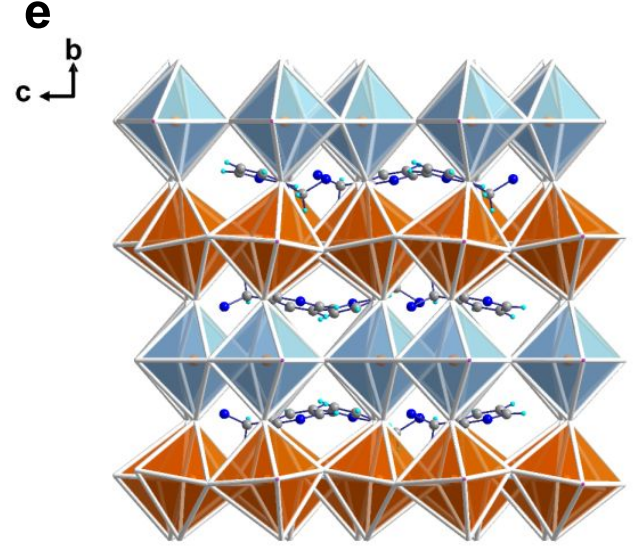

d
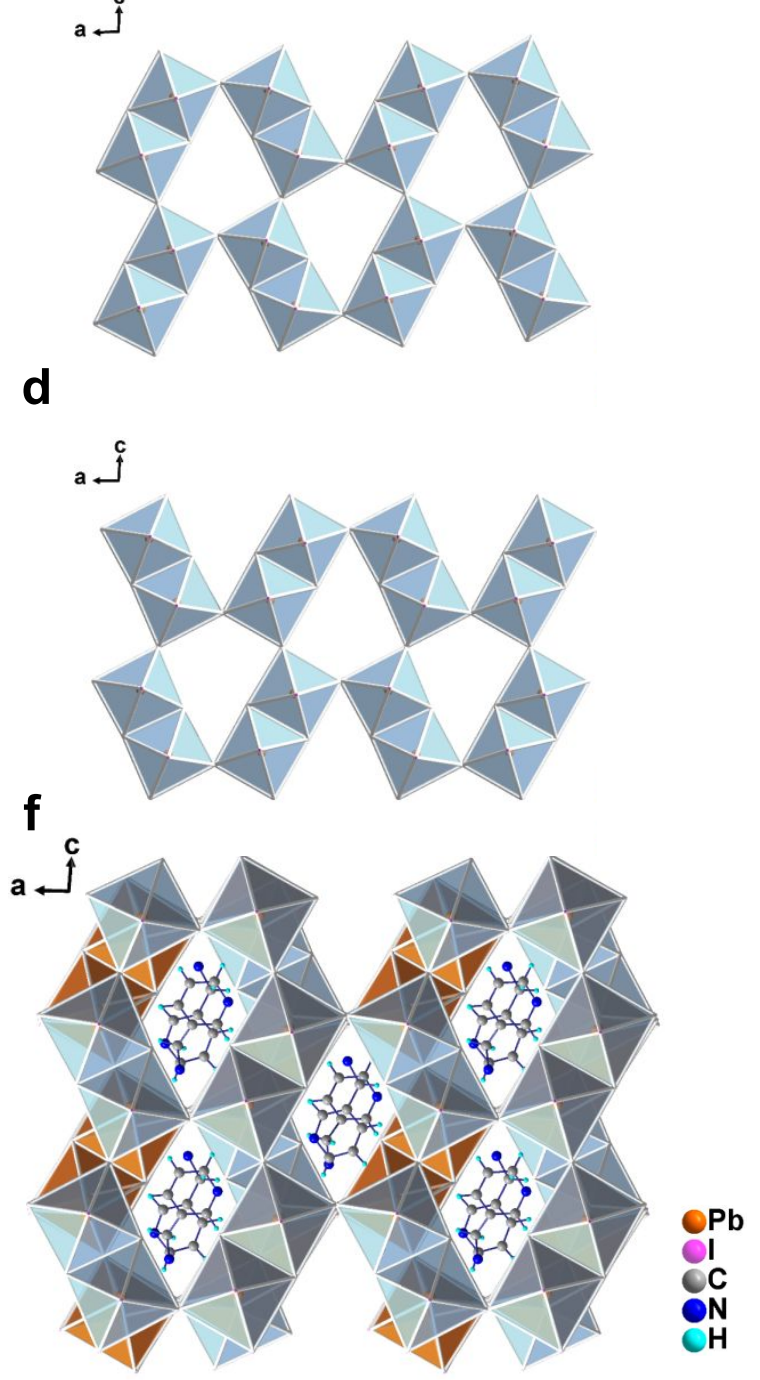

Figure 3. Crystal structure of (3AMPY) $\mathrm{Pb}_{2} \mathrm{I}_{6}$. (a) Connection motif of the octahedra for the bottom layer. (b) Connection motif for the second layer. (c) Connection motif for the third layer. (d) Connection motif for the top layer. The first and third layers are symmetry-related by a mirror plane, and the second and fourth layers are symmetry-related by a glide plane (organic cations omitted for clarity). (e) Crystal structure from side view. (f) Crystal structure from top view. The colors indicate the layers shown in (a)-(d). 


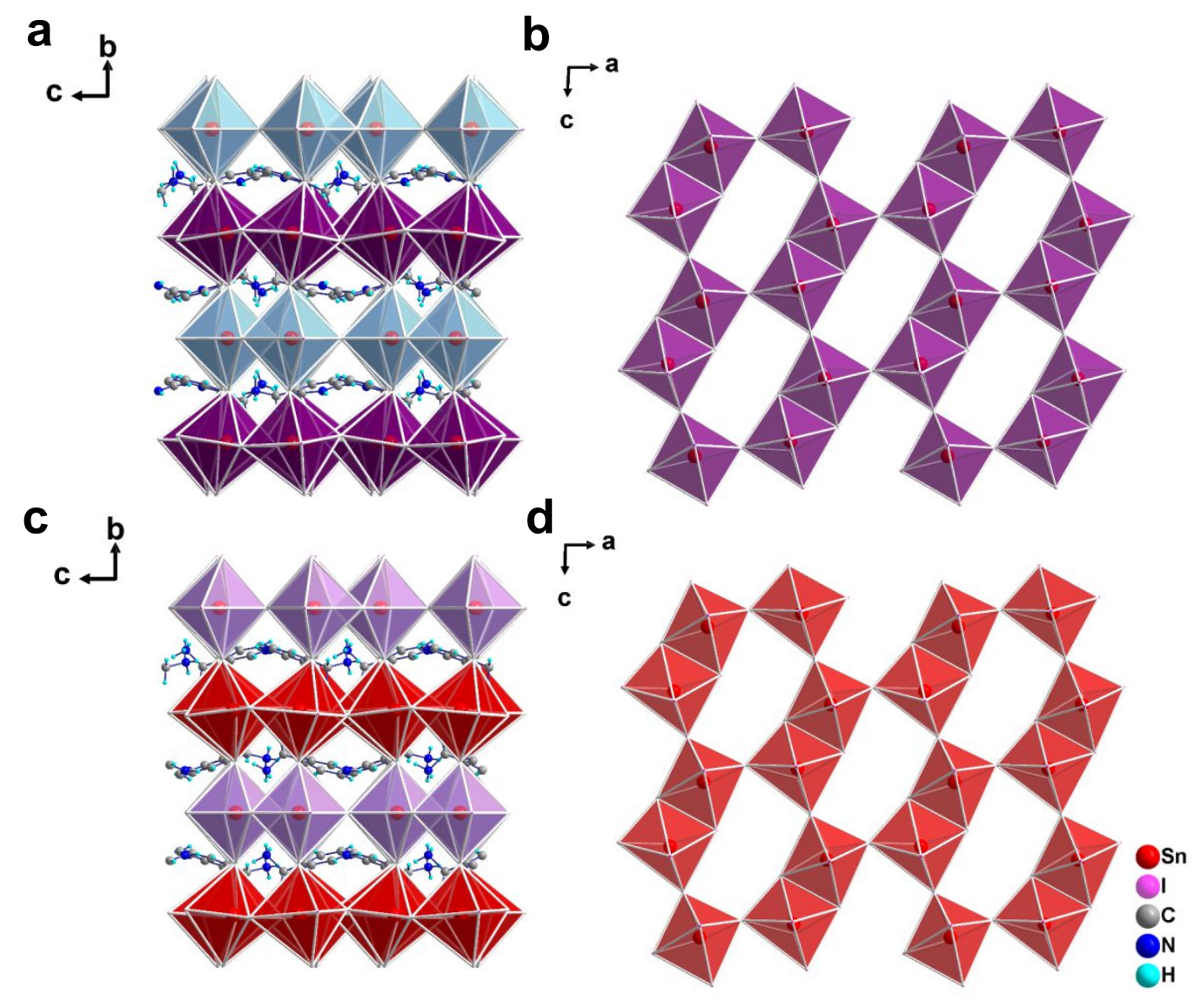

Figure 4. (a) Crystal structure of ( $3 \mathrm{AMPY}) \mathrm{Sn}_{2} \mathrm{I}_{6}$. (b) Connection motif of the octahedra for the bottom layer (organic cations omitted for clarity). (c) Crystal structure of (4AMPY) $\operatorname{Sn}_{2} \mathrm{I}_{6}$. (d) Connection motif of the octahedra for the bottom layer (organic cations omitted for clarity). 

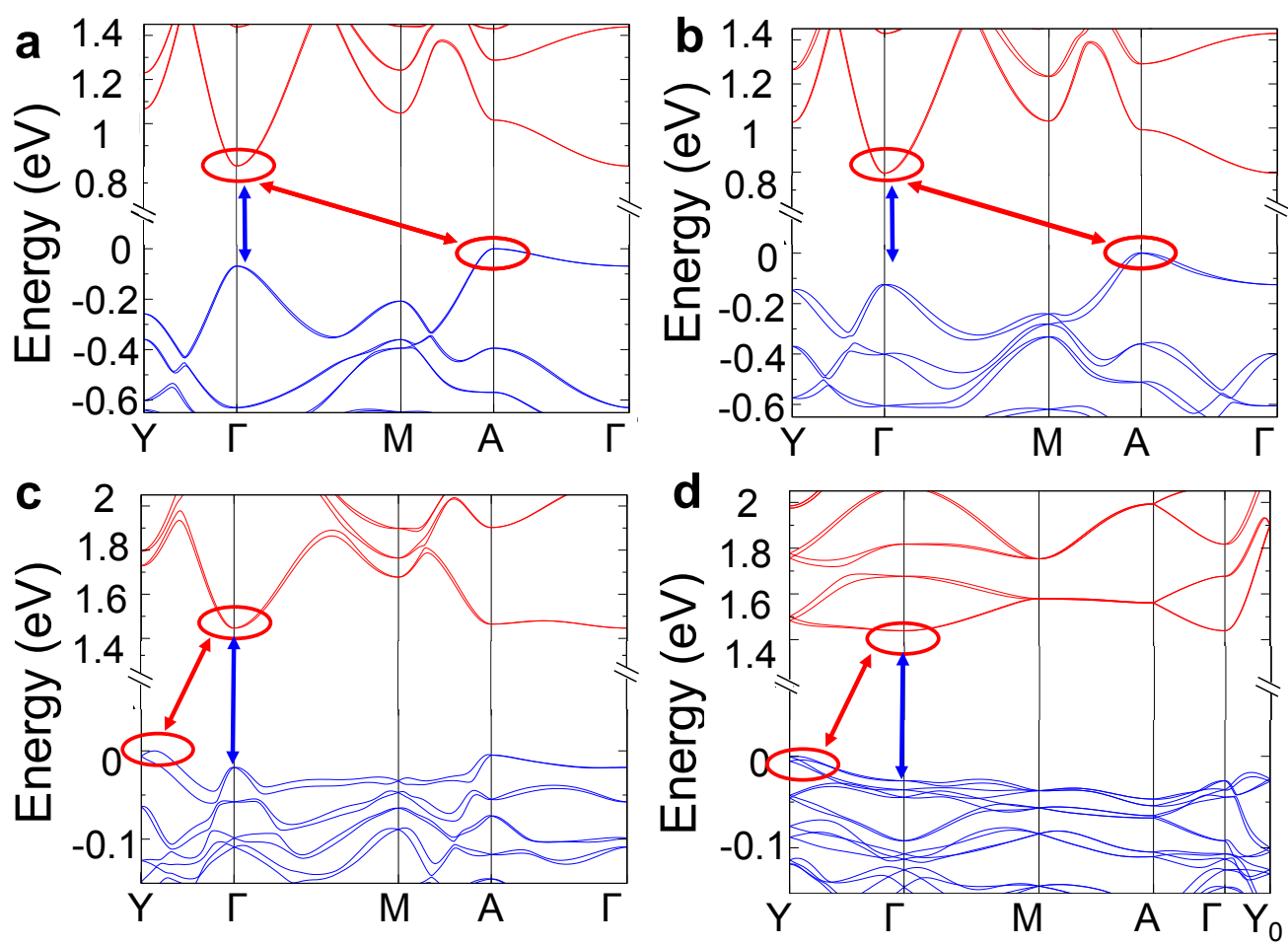

Figure 5. DFT calculations of band structures for (a) (3AMPY) $\mathrm{Sn}_{2} \mathrm{I}_{6}$, (b) (4AMPY) $\mathrm{Sn}_{2} \mathrm{I}_{6}$, (c) (3AMPY)Pb $\mathrm{I}_{6}$ and (d) (4AMPY)Pb ${ }_{2} \mathrm{I}_{6}$. The red circles indicate the VBM and CBM. The red arrows indicate the indirect bandgaps while the blue arrows indicate the direct bandgaps.
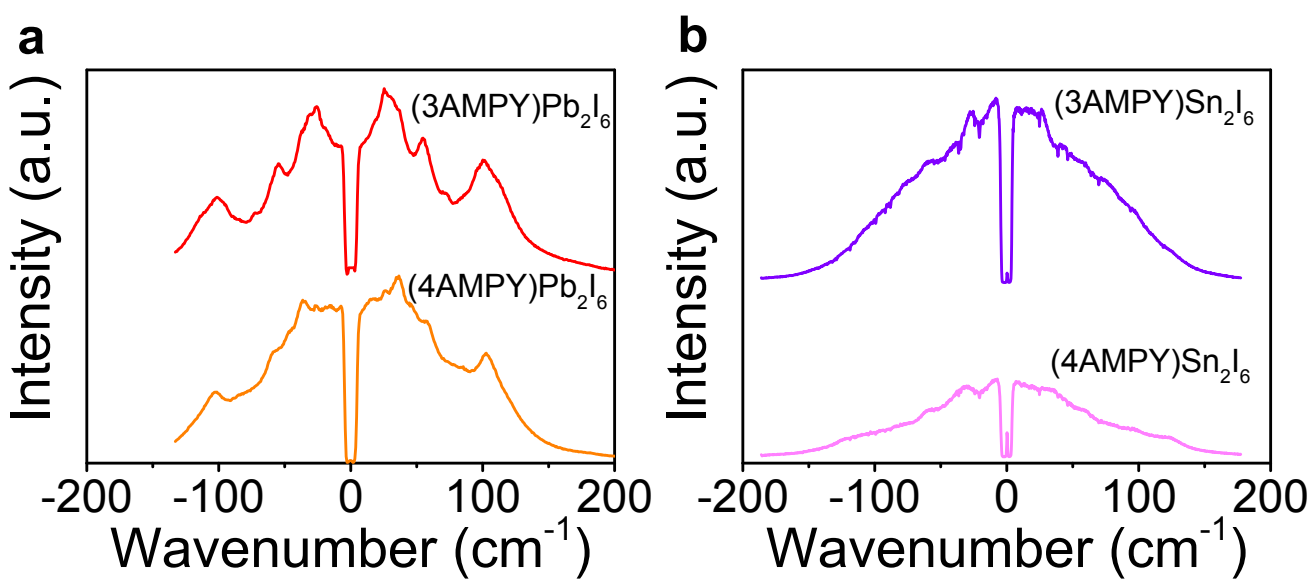

Figure 6. (a) Raman spectra of (3AMPY) $\mathrm{Pb}_{2} \mathrm{I}_{6}$ and (4AMPY)Pb $\mathrm{I}_{6}$. (b) Raman spectra of (3AMPY) $\mathrm{Sn}_{2} \mathrm{I}_{6}$ and (4AMPY) $\mathrm{Sn}_{2} \mathrm{I}_{6}$ (room temperature). 

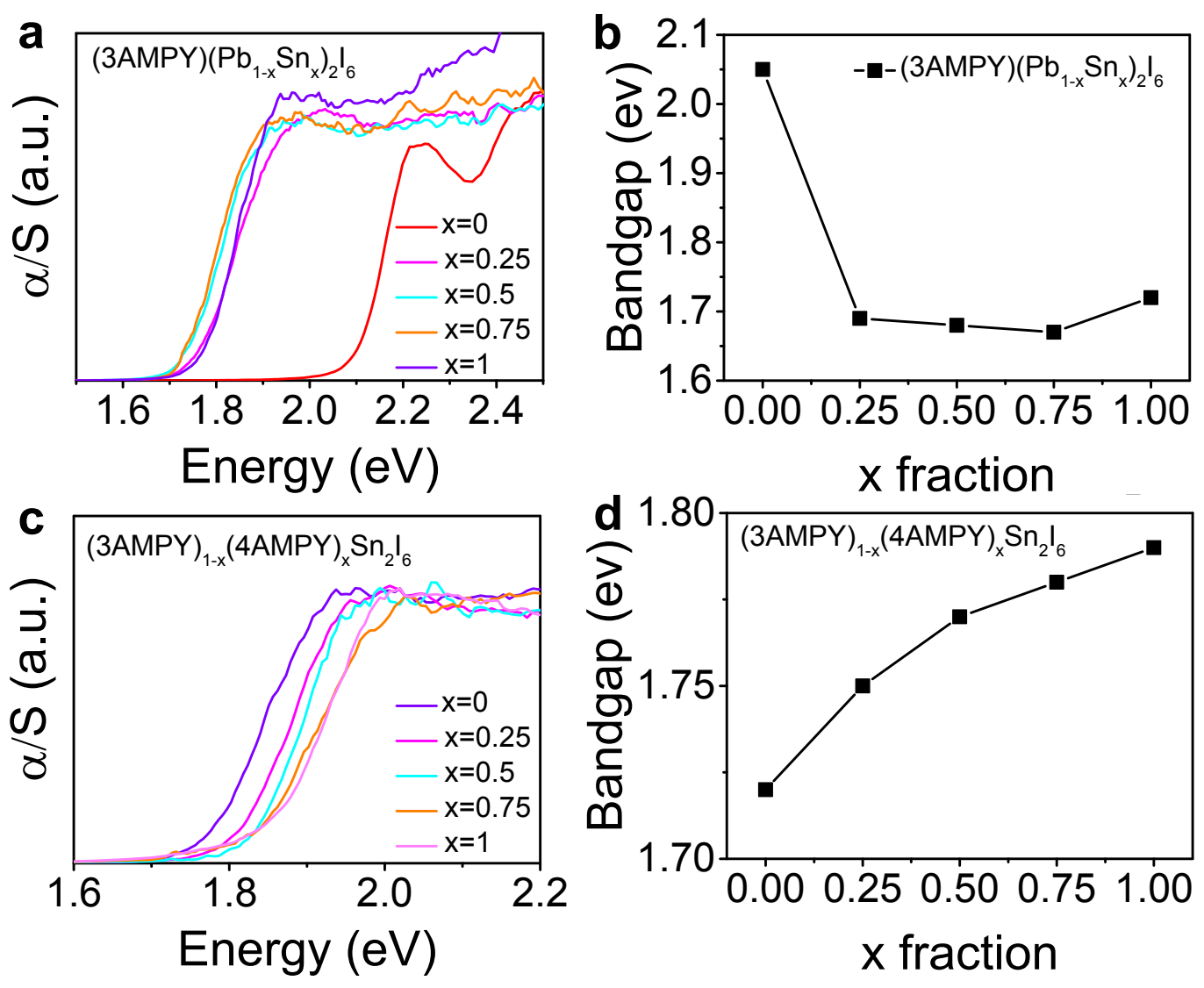

Figure 7. (a) The electronic absorption spectra for the (3AMPY) $\left(\mathrm{Pb}_{1-x} \mathrm{Sn}_{x}\right)_{2} \mathrm{I}_{6}$ series. (b) Bandgaps values extracted from Tauc plots assuming indirect bandgaps (Figure S4a). (c) Electronic absorption spectra for the (3AMPY) $)_{1-x}(4 \mathrm{AMPY})_{x} \mathrm{Sn}_{2} \mathrm{I}_{6}$ series. (d) Bandgaps values extracted from Tauc plots assuming indirect bandgaps (Figure S4b). Slightly different band gap values assuming direct electronic band gaps are provided in supporting information (Figure S5). 

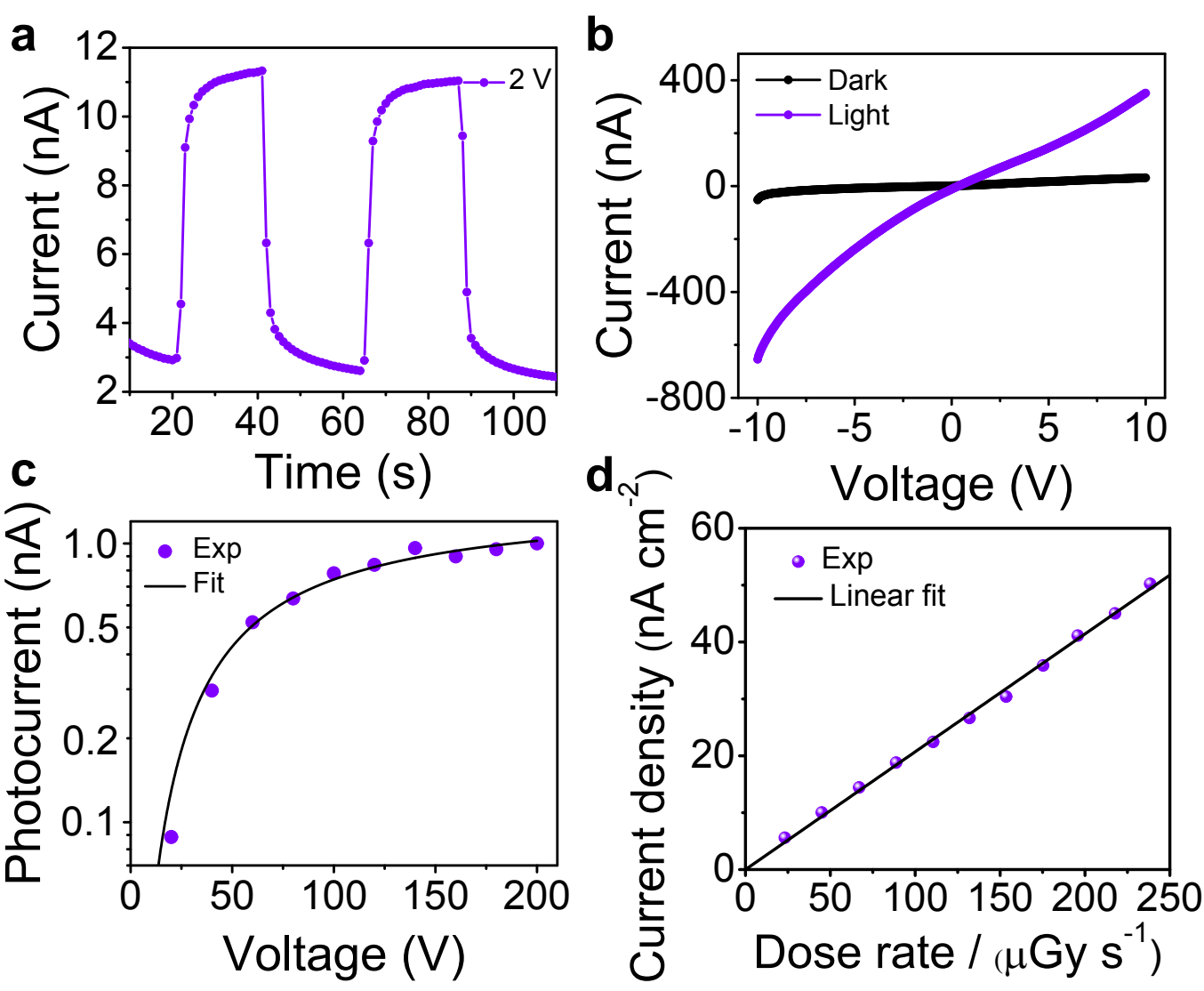

Figure 8. Optoelectronic response of the (3AMPY) $\mathrm{Pb}_{2} \mathrm{I}_{6}$ device. (a) On-off switching under ambient light with $2 \mathrm{~V}$ bias. (b) Current-voltage curve measured from $-10 \mathrm{~V}$ to $10 \mathrm{~V}$ under 10 $\mathrm{mW} / \mathrm{cm}^{2}$ illumination and in the dark. (c) Bias dependent X-ray photocurrent of the ( $3 \mathrm{AMPY} \mathrm{Pb}_{2} \mathrm{I}_{6}$ device under an uncollimated Ag X-ray tube source with a tube voltage of $50 \mathrm{kV}$. The Many equation was used for fitting. (d) X-ray sensitivity measurement of the (3AMPY) $\mathrm{Pb}_{2} \mathrm{I}_{6}$ device under a bias of $200 \mathrm{~V}$. The Ag X-ray tube voltage was $50 \mathrm{kV}$. 


\section{TOC Graphic}

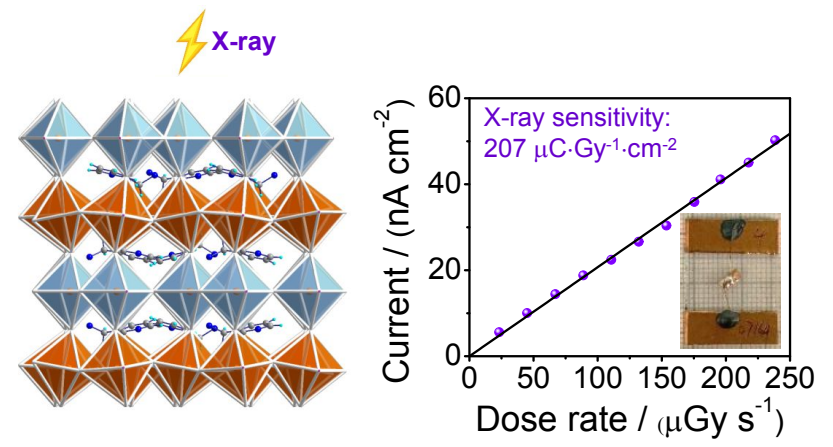

16

17

18

19

20

21

22

23

24

25

26

27

28

29

30

31

32

33

34

35

36

37

38

39

40

41

42

43

44

45

46

47

48

49

50

51

52

53

54

55

56

57

58

59

60 